\title{
Sucessão ecológica da vegetação arbórea em uma Floresta Estacional Semidecidual, Viçosa, MG, Brasil ${ }^{1}$
}

\author{
Alessandro de Paula ${ }^{5}$, Alexandre Francisco da Silva², Paulo De Marco Júnior ${ }^{3}$, \\ Flavio Antonio Maës dos Santos ${ }^{3}$ e Agostinho Lopes de Souza ${ }^{4}$
}

\author{
Recebido em 15/01/2002. Aceito em 07/11/2003
}

\begin{abstract}
RESUMO - (Sucessão ecológica da vegetação arbórea em uma Floresta Estacional Semidecidual, Viçosa, MG, Brasil). O trabalho foi realizado no município de Viçosa $\left(20^{\circ} 45^{\prime} \mathrm{S}\right.$ e $\left.42^{\circ} 07^{\prime} \mathrm{W}\right)$, no sudeste do Estado de Minas Gerais. O objetivo foi analisar as alterações ocorridas no estande entre os levantamentos realizados em 1984 e 1998. Para tanto, as espécies foram classificadas em três grupos ecológicos: pioneiras, secundárias iniciais e secundárias tardias. Também comparou-se a variação ocorrida na distribuição diamétrica e na densidade absoluta. As comparações foram analisadas estatisticamente, sendo utilizado o teste " $\mathrm{t}$ " de Student, o teste de qui-quadrado $\left(\chi^{2}\right)$. O estande estava composto por nove pioneiras, 56 secundárias iniciais e 29 secundárias tardias. Analisando as diferenças das médias dos números de indivíduos das secundárias iniciais, exceto Plinia glomerata (Berg.) Amshoff e Sorocea bonplandii (Daill.) Burger. Lanjow \& Boer, não foi observado estatisticamente acréscimo na densidade absoluta. A mesma situação pôde ser observada para as espécies pioneiras, não havendo exceções. Essas constatações revelam tendência de redução da importância desses grupos, ao passo que a única secundária tardia (Protium warmingianum March.) que pôde ser analisada, obteve estatisticamente aumento de sua densidade absoluta. Esses fatos demonstram melhoria nas condições de suporte da área para os grupos ecológicos mais avançados na escala sucessional.
\end{abstract}

Palavras-chave: sucessão ecológica, Floresta Estacional Semidecidual, grupos ecológicos

\begin{abstract}
Ecological succession of a tree community of semideciduous seasonal forest in Viçosa, Minas Gerais State, Brazil). This work was carried out at Viçosa $\left(20^{\circ} 45^{\prime} \mathrm{S}, 42^{\circ} 07^{\prime} \mathrm{W}\right)$ in the Southeastern region of Minas Gerais. The study examed the changes occurred in the stand between surveys done in 1984 and 1998. Species were then classified as pioneers, early secondary and late secondary. Changes in diametric distribution and absolute density were also investigated. Means were compared through student' $\mathrm{t}$ and square-chi $\left(\chi^{2}\right)$ tests. The stand showed to be constituted of nine pioneers, 56 early secondary, and 29 late secondary. Except for Plinia glomerata Berg.) Amshoff and Sorocea bonplandii (Daill.) Burger. Lanjow \& Boer, no increase in absolute density could be detected for the individuals from the group of early secondary. The same trend was observed with in the pioneer species, without exceptions. These findings point out a tendency for decreasing importance of these ecological groups. Protium warmingianum March., the only late secondary to be analyzed, showed a significant increase in its absolute density. Overall, these facts suggested an improvement in the conditions of the area for the support of more advanced ecological groups in the successional scale.
\end{abstract}

Key words: ecological succession, semideciduous seasonal forest, ecological groups

\section{Introdução}

A classificação das espécies em grupos ecológicos é ferramenta essencial para a compreensão da sucessão ecológica. A grande plasticidade apresentada pelas espécies dificulta a determinação dos critérios de classificação. Segundo Budowski (1965), as espécies pioneiras e secundárias iniciais são encontradas em áreas com condições climáticas e edáficas muito diferentes, o que lhes propicia ampla distribuição geográfica. Em florestas fechadas nãoperturbadas ou em estádios sucessionais mais avançados, o recrutamento dessas espécies está condicionado ao surgimento de clareiras. As espécies secundárias tardias têm como característica mais importante a deciduidade, que ocorre inclusive em áreas de alta pluviosidade (Budowski 1965). Muitas também são encontradas em hábitats secos ou florestas

\footnotetext{
Parte da Dissertação de Mestrado do primeiro Autor desenvolvida na Universidade Federal de Viçosa (UFV), auxílio financeiro FAPEMIG Universidade Federal de Viçosa, Departamento de Biologia Vegetal, CEP 36571-000, Viçosa, MG, Brasil

3 Universidade Federal de Viçosa, Departamento de Biologia Geral, CEP 36571-000, Viçosa, MG, Brasil

Universidade de Campinas, UNICAMP, Departamento de Botânica, C. Postal 6109, CEP 13081-970, Campinas, SP, Brasil

Universidade Federal de Viçosa, Departamento de Engenharia Florestal, CEP 36571-000, Viçosa, MG, Brasil

Autor para correspondência: alessandro_paula@ig.com.br
} 
decíduas, fazendo parte das espécies clímaces nessas áreas. Para esse autor, uma comunidade clímax é o produto final do processo sucessional, onde a relativa estabilidade não é certamente estática. Nessas comunidades, a mistura de espécies de diferentes grupos ecológicos é regra, mas geralmente ocorre o domínio de uma ou poucas espécies, sendo o endemismo também frequiente nesses casos.

Vários autores (Crestana et al. 1993; Tabarelli et al. 1993a; 1993b; Ferretti et al. 1995; Almeida \& Souza 1997; Dias et al. 1998), entre outros, embora tenham uma mesma idéia central, não concordam em relação à classificação das espécies por grupos ecológicos. Em suma, todas as classificações apontam para o sítio no qual a espécie é encontrada, estando assim diretamente relacionada com a luminosidade associada ao respectivo estrato. Embora essa seja a base da classificação, os limites que definem os grupos são muito tênues, fazendo com que algumas espécies possam ser incluídas em mais de um grupo. Mesmo em relação ao número de grupos, não há uma só definição, podendo ser três ou quatro, dependendo do critério utilizado.

Outra ferramenta utilizada para a compreensão da sucessão é a distribuição diamétrica. Nos sistemas temperados ineqüiâneos, a determinação da idade das árvores é realizada através da contagem dos anéis de crescimento (Daubenmire 1968). Nos sistemas tropicais, esse método torna-se impraticável uma vez que os anéis não são anuais, não sendo sua periodicidade bem definida. Nesse caso, para avaliar as idades das árvores utiliza-se a medição dos diâmetros, esperando que reflitam a estrutura de tamanho das populações (Daubenmire 1968; Harper 1977).

Supondo que cada espécie possua dinâmica própria de crescimento, a forma de agrupamento não refletirá com precisão a distribuição das idades dentro da floresta. Tanto é assim que, Moraes (1970), verificando a existência de periodicidade estacional no crescimento do tronco de 21 espécies florestais na Amazônia, observou que quando em um determinado período havia acréscimo na velocidade de crescimento da circunferência do tronco para uma espécie, isso verificava-se, de modo geral, em todos os seus indivíduos, o mesmo ocorrendo em relação à redução da velocidade do crescimento. Por isso, a distribuição diamétrica é hoje ferramenta muito importante, e tem sido utilizada freqüentemente em trabalhos de manejo.

Uma população pode ser classificada como clímax quando apresenta um domínio permanente do hábitat, ou seja, uma série completa de indivíduos distribuídos em cada classe de diâmetro ou idade, para cada espécie. Por outro lado, se as classes de diâmetros apresentam-se interrompidas ou truncadas, significa que o ciclo de vida da espécie não está se completando, o que indica que a mesma não pode ser considerada clímax no hábitat (Daubenmire 1968).

Este trabalho teve como objetivos classificar a vegetação arbórea em grupos ecológicos e caracterizar a fase de sucessão do estande, com base em levantamentos realizados nos anos de 1984 (Silva et al. 2000) e 1998 (Paula et al. 2002) em um trecho da Mata da Biologia da Universidade Federal de Viçosa.

\section{Material e métodos}

A área de estudo situa-se no câmpus da Universidade Federal de Viçosa (20³5' a $28^{\circ} 50^{\prime} \mathrm{S}$ e $42^{\circ} 45^{\prime}$ a $43^{\circ} 00^{\prime} \mathrm{W}$ ), na Zona da Mata de Minas Gerais, em altitude de $650 \mathrm{~m}$, numa encosta com declividade de até $45^{\circ}$ e em regeneração natural há 75 anos. Segundo Rizzini (1963), faz parte da unidade fitogeográfica de Floresta Atlântica, enquanto Veloso et al. (1991) enquadra-a na Formação da Floresta Estacional Semidecidual Montana.

O clima da região é do tipo $\mathrm{Cwb}$ (subtropical moderado úmido), segundo a classificação de Köppen, apresentando déficit hídrico no período de maio a setembro e um excedente de precipitação entre dezembro e março (Golfari 1975). As médias anuais de precipitação pluvial, obtidas entre os anos de 1961 e 1990, foi de 1.221,4mm (Departamento Nacional de Meteorologia 1992).

No presente trabalho, para que se pudesse representar com a maior fidelidade possível as variações paramétricas ocorridas durante os 14 anos decorridos entre os dois levantamentos, utilizou-se a mesma metodologia aplicada em 1984 por Silva et al. (2000). O método empregado foi o de parcelas (Mueller-Dombois \& Ellenberg 1974), sendo a amostragem realizada em um hectare, com parcelas contíguas de $10 \times 10 \mathrm{~m}$. Foram amostrados, no estrato arbóreo, tanto os indivíduos remanescentes do levantamento de 1984 quanto os novos que apresentassem perímetro de tronco igual ou maior do que $15 \mathrm{~cm}$ de circunferência a altura de $1,3 \mathrm{~m}$ do solo (PAP).

Os parâmetros fitossociológicos analisados foram os usuais em fitossociologia: densidade relativa (DR), dominância relativa (DoR) e frequiências absoluta (FA) e relativa (FR), utilizados na composição dos valores 
de cobertura (VC) e importância (VI), e interpretados segundo Mueller-Dombois \& Ellenberg (1974), Pielou (1975) e Rosot et al. (1982), utilizando-se o programa Fitopac 1 (Shepherd 1996).

Foram realizadas observações de campo para auxiliar na classificação das espécies em grupos ecológicos que, por ventura, não se enquadraram nos critérios propostos pelos autores consultados, devido à baixa abundância, ou mesmo por falta de registro na literatura.

As espécies foram distribuídas em três grupos, seguindo a classificação de Gandolfi et al. (1995), sendo eles:

Pioneiras $(\mathrm{P})$ - espécies que se desenvolvem em clareiras, nas bordas da floresta ou em locais abertos, sendo claramente dependentes de condições de maior luminosidade, não ocorrendo, em geral, no sub-bosque.

Secundárias iniciais (SI) - espécies que se desenvolvem em clareiras pequenas ou mais raramente no subbosque, em condições de algum sombreamento. Podem também ocorrer em áreas de antigas clareiras, nesse caso ao lado de espécies pioneiras.

Secundárias tardias (ST) - espécies que se desenvolvem exclusivamente em sub-bosque permanentemente sombreado e, nesse caso, pequenas árvores ou espécies arbóreas de grande porte que se desenvolvem lentamente em ambientes sombreados, podendo alcançar o dossel ou serem emergentes.

$\mathrm{O}$ autor supracitado evita a denominação de espécie clímax, em primeiro lugar para evitar a discussão sobre este conceito e, em segundo, por reconhecer que muitas espécies típicas de sub-bosque ocorrem tanto nos estádios mais maduros, como em outras etapas do processo sucessional. Sendo assim, optou-se por adotar apenas três categorias sucessionais sugeridas.

Para o agrupamento dos indivíduos, as classes diamétricas foram definidas com amplitude de cinco centímetros, sendo o primeiro centro de classe estabelecido em $7,5 \mathrm{~cm}$.

Também foi realizada a distribuição das espécies em classes de altura, que foi tomada com o auxílio de um telêmetro. A floresta foi segmentada em três estratos verticais: inferior, médio e superior. $\mathrm{O}$ critério de estratificação tem por base a altura total $\left(\mathrm{h}_{1}\right)$ média e o seu respectivo desvio-padrão (Agostinho Lopes de Souza, comunicação pessoal):

Estrato inferior: árvores com $\mathrm{h}_{1}<(\overline{\mathrm{h}}-1 \mathrm{~s})$;

Estrato médio: árvores com $(\bar{h}-1 \mathrm{~s}) \leq \mathrm{h}_{1}<(\overline{\mathrm{h}}+1 \mathrm{~s})$; Em que:

e Estrato superior: árvores com $\mathrm{h}_{1} \leq(\overline{\mathrm{h}}+1 \mathrm{~s})$.

$\overline{\mathrm{h}}=$ média das alturas totais $\left(\mathrm{h}_{1}\right)$ dos indivíduos amostrados;

$\mathrm{s}=$ desvio-padrão das alturas totais $\left(\mathrm{h}_{1}\right)$ dos indivíduos amostrados; e

$1=1,2, \ldots, \mathrm{N}$ indivíduos amostrados.

$\mathrm{Na}$ representação gráfica, as distribuições das alturas para as espécies amostradas em cada traço vertical corresponde à diferença entre a altura total do indivíduo mais alto e a altura total do menor indivíduo. $\mathrm{O}$ ponto corresponde à altura média calculada para a espécie.

Com o intuito de analisar estatisticamente as variações ocorridas na densidade absoluta das espécies durante os dois levantamentos, utilizou-se o teste " $\mathrm{t}$ " de Student para amostras dependentes (Sokal \& Rohlf 1984).

Foram analisadas as densidades absolutas médias $\left(\overline{\mathrm{DA}}_{\mathrm{i}}\right)$ por espécie, obtidas nos levantamentos de 1984 e 1998.

$$
\left(\overline{D A}_{i}\right)=\frac{n_{i}}{u_{t}}
$$

Onde:

$\mathrm{n}_{\mathrm{i}}=$ número de indivíduos da i-ésima espécie; $\mathrm{e}$

$\mathrm{u}_{\mathrm{t}}=$ número total de subparcelas.

As hipóteses testadas foram:

$\mathrm{H}_{0}$ - a densidade absoluta média da espécie em 1984 é igual a encontrada em 1998.

$\mathrm{H}_{\mathrm{a}}$ - a densidade absoluta média da espécie em 1984 é diferente da encontrada em 1998.

Também foram analisadas as variações ocorridas na freqüência absoluta $\left(\mathrm{FA}_{\mathrm{i}}\right)$ das espécies mais freqüentes, entre os levantamentos de 1984 e 1998. Para esse fim, utilizou-se o teste de qui-quadrado $\left(\chi^{2}\right)$ (Sokal \& Rohlf 1984).

As hipóteses testadas foram:

$\mathrm{H}_{0}$ - a frequiência absoluta da espécie em 1984 é igual à encontrada em 1998.

$\mathrm{H}_{\mathrm{a}}$ - a frequiência absoluta da espécie em 1984 é diferente da encontrada em 1998.

Para comparar as diferenças ocorridas no número de indivíduos dos três grupos ecológicos entre os dois levantamentos, utilizou-se o teste de qui-quadrado $\left(\chi^{2}\right)$. A hipótese nula era da igualdade da proporção de espécies nos grupos nos dois levantamentos. Um resultado significativo neste teste, no entanto, apenas mostra que houve uma diferença em algum dos grupos, sem identificá-lo. Como este teste apresenta dois graus 
de liberdade, procederam-se duas comparações planejadas de acordo com o sugerido por Zar (1984), para evitar o problema das comparações múltiplas ("experiment wise error rate"). Estas comparações, com um grau de liberdade e definidas a priori, foram:

a) Iniciais (pioneiras e secundárias iniciais) $\times$ secundárias tardias - comparam-se variações ocorridas no número de indivíduos entre o grupo das iniciais $\times$ o grupo das secundárias tardias, nos levantamentos de 1984 e 1998;

b) Pioneiras $\times$ secundárias iniciais - comparam-se variações ocorridas no número de indivíduos entre o grupo das pioneiras e o grupo das secundárias iniciais, nos levantamentos de 1984 e 1998.

\section{Resultados e discussão}

Grupos ecológicos - A amostragem indicou composição de nove espécies pioneiras $(9,6 \%), 56$ secundárias iniciais $(59,6 \%)$ e 29 secundárias tardias $(30,6 \%)$. Na Tab. 1 pode-se observar que em todos os parâmetros fitossociológicos se destaca o grupo das secundárias iniciais. A Tab. 2 traz a relação das espécies encontradas no levantamento fitossociológico de 1998 (Silva et al. 2000), inclui a classificação dos respectivos grupos ecológicos.

Considerando a baixa representatividade florística das espécies pioneiras e o número de secundárias tardias, encontrou-se relação que exprime um estádio intermediário no tocante ao desenvolvimento sucessional da floresta. Nesse caso, a maior influência foi exercida pelas espécies secundárias iniciais, estando as secundárias tardias também presentes com relativa importância. Já as espécies pioneiras parecem estar, em sua maioria, restritas a clareiras formadas por quedas de galhos ou de árvores isoladas, processo natural dentro da dinâmica do desenvolvimento da floresta.

Tabela 1. Valores dos parâmetros da estrutura horizontal por grupo ecológico, das espécies amostradas em 1998 (Silva et al. 2000) na Mata da Biologia, situada no câmpus da Universidade Federal de Viçosa, Viçosa, $M G$. DR = densidade relativa, $\mathrm{DoR}=$ dominância relativa, $\mathrm{FR}=$ frequiência relativa, $\mathrm{VI}=$ Valor de importância, $\mathrm{VC}=$ Valor de cobertura.

\begin{tabular}{lrrrrr}
\hline Grupos ecológicos & $\begin{array}{l}\text { DR } \\
(\%)\end{array}$ & $\begin{array}{l}\text { DoR } \\
(\%)\end{array}$ & $\begin{array}{l}\text { FR } \\
(\%)\end{array}$ & $\begin{array}{r}\text { VI } \\
(\%)\end{array}$ & $\begin{array}{r}\text { VC } \\
(\%)\end{array}$ \\
\hline Pioneiras & 8,90 & 7,49 & 11,41 & 27,76 & 16,35 \\
Secundárias iniciais & 80,98 & 85,73 & 75,74 & 242,37 & 166,72 \\
Secundárias tardias & 10,12 & 6,78 & 12,85 & 29,87 & 16,93 \\
\hline
\end{tabular}

A simples caracterização do estádio de sucessão com base em uma listagem florística, por vezes pode não expressar fielmente a realidade. Muitas informações importantes podem não estar sendo contempladas por essa análise. Para melhor compreensão do estádio de desenvolvimento de um estande florestal, torna-se também necessária a avaliação dos parâmetros fitossociológicos, obtendo assim caracterização da estrutura horizontal.

Silva Filho \& Engel (1993) encontraram, entre as 20 primeiras espécies ordenadas decrescentemente pelo valor de importância, duas típicas de início de sucessão, 12 de estádios mais avançados e cinco de estádio final. Segundo os autores, esses dados indicam que o fragmento se encontra próximo a uma fase de maturidade, em equilíbrio dinâmico.

Analisando a densidade relativa por grupo, observou-se o expressivo valor apresentado pelas secundárias iniciais. Esse dado influenciou decisivamente na dominância relativa, que foi muito superior ao apresentado pelo grupo das secundárias tardias.

$\mathrm{O}$ alto valor de freqüência relativa apresentado pelo grupo das espécies de estádios iniciais (pioneiras e secundárias iniciais) demonstrou o quão dispersas estavam na área amostrada. Esse fato pode ser justificado pelo relevo onde as parcelas foram alocadas. Devido à sua inclinação, de até $45^{\circ} \mathrm{em}$ alguns locais, o dossel por vezes não é contínuo, propiciando grande incidência de luz nos estratos inferiores. Essa luminosidade favorece o desenvolvimento de espécies do grupo das secundárias iniciais, que suportam certo grau de sombreamento. Apesar dos dados relativos à florística e à estrutura horizontal apontarem para um estádio intermediário de sucessão, o relevo é decisivo no tocante ao desenvolvimento desse grupo de espécies. Assim, a inexistência de dossel fechado, por ação de declividade acentuada, deve ser observada na classificação do estádio de desenvolvimento da fitocenose estudada. Em um relevo plano existe a possibilidade de formação de dossel contínuo que, nesse caso, exerce influência sobre o estádio de desenvolvimento sucessional.

Os dados sobre o número de indivíduos por grupo ecológico encontrado nos dois levantamentos realizados (Tab. 3) mostraram que houve redução no número de indivíduos do grupo das espécies pioneiras, e acréscimo tanto no grupo das secundárias iniciais, quanto no das secundárias tardias.

Pagano et al. (1995) estudaram a dinâmica florística e fitossociológica de uma Floresta Estacional Semidecidual, com base em dois levantamentos realizados 
Tabela 2. Lista das espécies com seus respectivos grupos ecológicos (GE), número de indivíduos encontrado em cada estrato e dispersão de altura (d.H) no levantamento realizado em 1998, na Mata da Biologia, situada no câmpus da Universidade Federal de Viçosa, Viçosa, MG.

\begin{tabular}{|c|c|c|c|c|c|}
\hline \multirow[t]{2}{*}{ Espécie } & \multirow[t]{2}{*}{ GE } & \multicolumn{3}{|c|}{ Número de indivíduos por estrato } & \multirow[t]{2}{*}{ d.H } \\
\hline & & Inferior & Médio & Superior & \\
\hline 1. Acacia polyphylla DC. & SI & & 1 & & 0,0 \\
\hline 2. Acanthinophyllum ilicifolium (Spreng.) Burger & SI & 1 & 3 & 1 & 3,9 \\
\hline 3. Allophylus edulis Radlk. ex Warm. & SI & & 18 & 7 & 2,8 \\
\hline 4. Amaioua guianensis Aubl. & SI & & 12 & & 1,6 \\
\hline 5. Anadenanthera colubrina (Benth.) Brenan & SI & & 8 & 55 & 5,2 \\
\hline 6. Andira fraxinifolia Benth. & SI & 1 & 1 & & 4,0 \\
\hline 7. Aniba firmula Mez. & ST & & 1 & & 0,0 \\
\hline 8. Apuleia leiocarpa Macbride & SI & & 47 & 23 & 3,8 \\
\hline 9. Aspidosperma olivaceum Muell. Arg. & ST & 1 & 3 & & 2,4 \\
\hline 10. Astronium fraxinifolium Schott & ST & & 2 & 2 & 4,1 \\
\hline 11. Attalea dubia Burret & $\mathrm{P}$ & & 3 & & 1,7 \\
\hline 12. Bathysa nicholsonii K. Schum. & SI & & 3 & & 0,6 \\
\hline 13. Brosimum glaziovii Taub. & SI & & 13 & 3 & 2,7 \\
\hline 14. Campomanesia xanthocarpa Berg. & ST & & 2 & & 1,8 \\
\hline 15. Cariniana estrellensis Kuntze & ST & & 2 & & 1,6 \\
\hline 16. Cariniana legalis Kuntze & ST & & 2 & 1 & 6,2 \\
\hline 17. Carpotroche brasiliensis Endl. & ST & & 8 & & 2,8 \\
\hline 18. Casearia arborea Urb. & SI & 1 & 15 & 2 & 4,0 \\
\hline 19. Casearia decandra Jacq. & SI & & 7 & 8 & 3,4 \\
\hline 20. Casearia obliqua Spreng. & SI & & 2 & 2 & 2,9 \\
\hline 21. Casearia ulmifolia Cambess. & SI & 2 & 96 & 56 & 3,5 \\
\hline 22. Cecropia hololeuca Miq. & $\mathrm{P}$ & & & 1 & 0,0 \\
\hline 23. Cedrela fissilis Vell. & SI & & 1 & & 0,0 \\
\hline 24. Chorisia speciosa A. St.-Hil. & SI & & 8 & 2 & 4,3 \\
\hline 25. Chrysophylum gonocarpum Engl. & ST & 2 & 13 & & 2,0 \\
\hline 26. Chrysophylum marginatum Radlk. & ST & & 2 & & 1,5 \\
\hline 27. Copaifera langsdorffii Desf. & SI & & 2 & 4 & 3,2 \\
\hline 28. Cordia sellowiana Cham. & SI & & 2 & 3 & 0,3 \\
\hline 29. Cordia sylvestris Fresen. & SI & & & 1 & 3,3 \\
\hline 30. Coutarea hexandra K. Schum. & SI & 1 & 63 & 3 & 2,4 \\
\hline 31. Croton floribundus Spreng. & $\mathrm{P}$ & & 1 & & 0,0 \\
\hline 32. Cybistax antisyphilitica Mart. & SI & & 2 & & 0,7 \\
\hline 33. Dalbergia nigra Allem. ex Benth. & SI & & 9 & 4 & 2,8 \\
\hline 34. Endlicheria paniculata (Spreng.) Macbride & ST & & & 2 & 0,7 \\
\hline 35. Eriotheca candolleana (K. Schum.) A. Robyns & SI & 1 & 4 & & 2,1 \\
\hline 36. Erythroxylum pelleterianum A. St.-Hil. & SI & & 2 & & 0,3 \\
\hline 37. Eugenia leptoclada Berg. & ST & & 7 & & 2,4 \\
\hline 38. Eugenia strictosepala Kiaersk. & ST & & 2 & & 1,2 \\
\hline 39. Eugenia uniflora Berg. & ST & & 1 & & 0,0 \\
\hline 40. Guapira opposita (Vell.) Reitz & SI & & 1 & & 0,0 \\
\hline 41. Guettarda viburnoides Cham. \& Schlecht. & SI & & 3 & 1 & 3,7 \\
\hline 42. Hortia arborea Engl. & ST & & 1 & & 0,0 \\
\hline 43. Inga striata Benth. & SI & & 1 & & 0,0 \\
\hline 44. Ixora gardneriana Benth. & ST & & 2 & 1 & 3,5 \\
\hline 45. Jacaranda macrantha Cham. & SI & 1 & 10 & & 1,0 \\
\hline 46. Licania spicata Hook. f. & SI & & 4 & & 2,8 \\
\hline 47. Lonchocarpus guilleminianus (Tul.) Malme & SI & & 1 & & 0,0 \\
\hline 48. Luehea grandiflora Mart. & $\mathrm{P}$ & & 12 & 6 & 3,7 \\
\hline 49. Mabea fistulifera Mart. & $\mathrm{P}$ & & 4 & & 2,1 \\
\hline 50. Machaerium brasiliense Vog. & SI & & 2 & & 0,2 \\
\hline 51. Machaerium nictitans (Vell.) Benth. & $\mathrm{P}$ & 2 & 41 & 12 & 3,6 \\
\hline 52. Maclura tinctoria D. Don ex Steud. & SI & & 3 & & 2,2 \\
\hline 53. Matayba elaeagnoides Radlk. & SI & & 4 & & $\begin{array}{c}0,8 \\
\text { ntinu }\end{array}$ \\
\hline
\end{tabular}


Tabela 2 (continuação)

\begin{tabular}{|c|c|c|c|c|c|}
\hline \multirow[t]{2}{*}{ Espécie } & \multirow[t]{2}{*}{ GE } & \multicolumn{3}{|c|}{ Número de indivíduos por estrato } & \multirow[t]{2}{*}{ d.H } \\
\hline & & Inferior & Médio & Superior & \\
\hline 54. Matayba guianensis Aubl. & SI & 1 & 2 & & 3,4 \\
\hline 55. Maytenus aquifolium Mart. & ST & 1 & 1 & & 1,0 \\
\hline 56. Mollinedia argyrogyna Perkins & SI & & 2 & & 1,5 \\
\hline 57. Myrciafallax DC. & SI & & 1 & & 0,0 \\
\hline 58. Myrcia sphaerocarpa DC. & SI & 1 & 8 & & 3,0 \\
\hline 59. Myrciaria axillaris Berg. & SI & 1 & 13 & & 1,5 \\
\hline 60. Myroxylon peruiferum Linn. f. & ST & & 1 & 1 & 11,5 \\
\hline 61. Nectandra lanceolata Ness \& Mart. ex Ness & ST & & 1 & & 0,0 \\
\hline 62. Ocotea dispersa $\mathrm{Mez}$ & SI & & 4 & & 2,0 \\
\hline 63. Ocotea indecora Schott ex Meissn. & ST & & 1 & & 0,0 \\
\hline 64. Ocotea odorifera (Vell.) J.G. Rohwer & ST & & 9 & 2 & 4,0 \\
\hline 65. Ocotea pubescens Ness & ST & & 1 & & 0,0 \\
\hline 66. Ocotea pulchella Mart. & SI & & & 1 & 0,0 \\
\hline 67. Peltophorum dubium Taub. & SI & & 3 & 5 & 4,7 \\
\hline 68. Persea pyrifolia Ness & SI & & 2 & & 0,6 \\
\hline 69. Picramnia regnelli Engl. & SI & & 1 & & 0,0 \\
\hline 70. Picramnia sp. & SI & & 1 & & 0,0 \\
\hline 71. Piptadenia gonoacantha Macbride & $\mathrm{P}$ & 7 & 53 & 12 & 4,3 \\
\hline 72. Platymiscium pubescens Micheli & ST & & 1 & & 0,0 \\
\hline 73. Platypodium elegans Vog. & SI & & 1 & & 0,0 \\
\hline 74. Plinia glomerata (Berg.) Amshoff & SI & 14 & 13 & & 1,1 \\
\hline 75. Pouteria laurifolia Radlk. & ST & & 1 & & 0,0 \\
\hline 76. Protium warmingianum March. & ST & & 97 & 3 & 2,4 \\
\hline 77. Prunus sellowii Koehne & SI & & 3 & 1 & 4,6 \\
\hline 78. Psychotria carthagenensis Jacq. & SI & 1 & & & 0,0 \\
\hline 79. Pterocarpus rohrii Vahl & SI & 1 & 5 & 2 & 5,0 \\
\hline 80. Qualea jundiahy Warm. & ST & & 2 & & 1,2 \\
\hline 81. Rollinia sylvatica (A. St.-Hil) Mart. & SI & & 55 & 7 & 2,3 \\
\hline 82. Sapium glandulatum $\mathrm{Pax}$ & $\mathrm{P}$ & & & 2 & 1,6 \\
\hline 83. Seguieria americana Linn. & SI & & 6 & & 2,9 \\
\hline 84. Siparuna guianense Aubl. & SI & 33 & 94 & & 1,4 \\
\hline 85. Sorocea bonplandii (Baill.) Burger, Lanjow \& Boer & SI & 7 & 506 & 10 & 2,2 \\
\hline 86. Sparattosperma leucanthum Schum & SI & & 6 & 3 & 4,3 \\
\hline 87. Swartzia elegans Schott & $\mathrm{ST}$ & & 1 & & 0,0 \\
\hline 88. Trichilia elegans A. Juss. & ST & & 1 & & 0,0 \\
\hline 89. Trichilia pallida $\mathrm{Sw}$. & SI & 8 & 121 & & 1,5 \\
\hline 90. Vitex megapotamica (Spreng.) Moldenke & SI & & 2 & 1 & 3,3 \\
\hline 91. Xylopia sericea A. St.-Hil. & SI & & 2 & & 2,5 \\
\hline 92. Zanthoxylum rhoifolium Lam. & $\mathrm{P}$ & & 3 & 3 & 5,4 \\
\hline 93. Zeyheria tuberculosa Bur. ex Verlot & ST & & 1 & 1 & 7,3 \\
\hline 94. Zollernia ilicifolia Vog. & $\mathrm{ST}$ & & 2 & & 1,6 \\
\hline Total & & 88 & 1484 & 254 & \\
\hline
\end{tabular}

com intervalo de dez anos. Apesar do primeiro levantamento ter utilizado o método de quadrantes e o segundo o de parcelas, algumas conclusões dos autores corroboram os dados obtidos no presente estudo. No grupo das pioneiras, praticamente não ocorreram alterações no tocante ao número de indivíduos. Já para o grupo de espécies de submata, secundárias iniciais e secundárias tardias, houve algumas modificações no número de indivíduos. Levando em consideração o histórico da área, onde não consta a presença de atividades antrópicas impactantes entre os dois levantamentos, os autores constataram que na ausência de impactos, houve menor oportunidade para o surgimento de pioneiras e melhores condições para o estabelecimento de indivíduos de estádios mais maduros, exceto nos sítios de clareiras naturais.

Distribuição diamétrica - Na Fig. 1, pode-se observar que as distribuições diamétricas da comunidade como um todo, nos levantamentos de 1984 e de 1998, dos 
Tabela 3. Número de indivíduos vivos por hectare, por grupo ecológico, amostrados nos levantamentos realizados em 1984 e 1998, na Mata da Biologia, situada no câmpus da Universidade Federal de Viçosa, Viçosa, MG.

\begin{tabular}{lrrrr}
\hline \multirow{2}{*}{ Grupos ecológicos } & \multicolumn{3}{c}{ Número de indivíduos vivos } \\
\cline { 2 - 5 } & \multicolumn{2}{c}{1984} & \multicolumn{2}{c}{1998} \\
\hline Pioneiras & 197 & $11,6 \%$ & 162 & $8,9 \%$ \\
Secundárias iniciais & 1.331 & $78,4 \%$ & 1.479 & $81,0 \%$ \\
Secundárias tardias & 163 & $9,6 \%$ & 185 & $10,1 \%$ \\
Indeterminadas & 7 & $0,4 \%$ & - & - \\
Total & 1.698 & $100 \%$ & 1.826 & $100 \%$ \\
\hline
\end{tabular}

grupos ecológicos das pioneiras, secundárias iniciais e secundárias tardias, apresentam forma de "J" reverso, de acordo com a descrição feita por Meyer (1952). Segundo esse autor, a distribuição diamétrica em florestas inequiiâneas tendem a formar um "J" reverso, estando o maior número de indivíduos dispostos nas menores classes, reduzindo gradativamente em direção às maiores. As distribuições apresentaram-se desbalanceadas, ou seja, a razão entre o número de indivíduos de classes subseqüentes não é constante (Liocourt 1898 apud Meyer 1952).

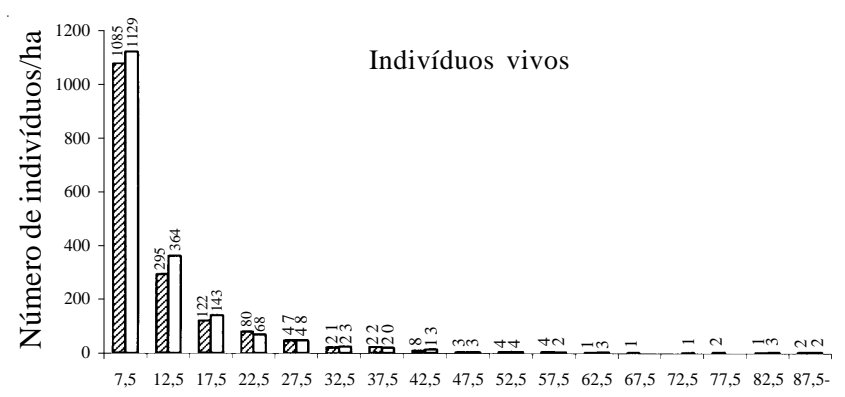

Centro de classes de diâmetro $(\mathrm{cm})$

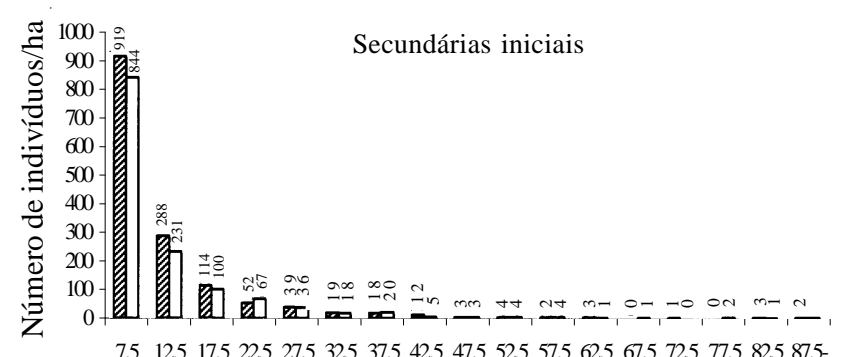

Centro de classes de diâmetro $(\mathrm{cm})$
Na Fig. 2, observa-se que as espécies pioneiras Machaerium nictitans e Piptadenia gonoacantha, apresentaram distribuição diamétrica estreita em forma de "J" reverso, tanto em 1984 quanto em 1998. Durante os 14 anos, Machaerium nictitans perdeu seu único indivíduo de grande porte.

Nas maiores classes diamétricas (a partir de $57,5 \mathrm{~cm}$ ), todos os indivíduos amostrados foram de Anadenanthera colubrina, secundária inicial. Na distribuição diamétrica para essa espécie (Fig. 3) observa-se que o ingresso nas menores classes se apresentou bastante reduzido, enquanto que nas classes intermediárias a densidade é bem mais alta. Esse registro evidencia que em período anterior, as condições para o recrutamento da espécie eram mais favoráveis. De acordo com Silva Júnior \& Silva (1988), os histogramas de frequiência das classes de diâmetros podem retratar os acontecimentos por que passou uma determinada floresta. Assim, pode-se supor que ocorreram perturbações como ataque de insetos, doenças, não-estabelecimento de plântulas e baixa taxa de germinação.

Nos levantamentos de 1984 e 1998, as distribuições diamétricas de Apuleia leiocarpa apresentaram-se estreitas, restritas às classes de menores de diâmetro (Fig. 4). Acredita-se que, juntamente com a evolução
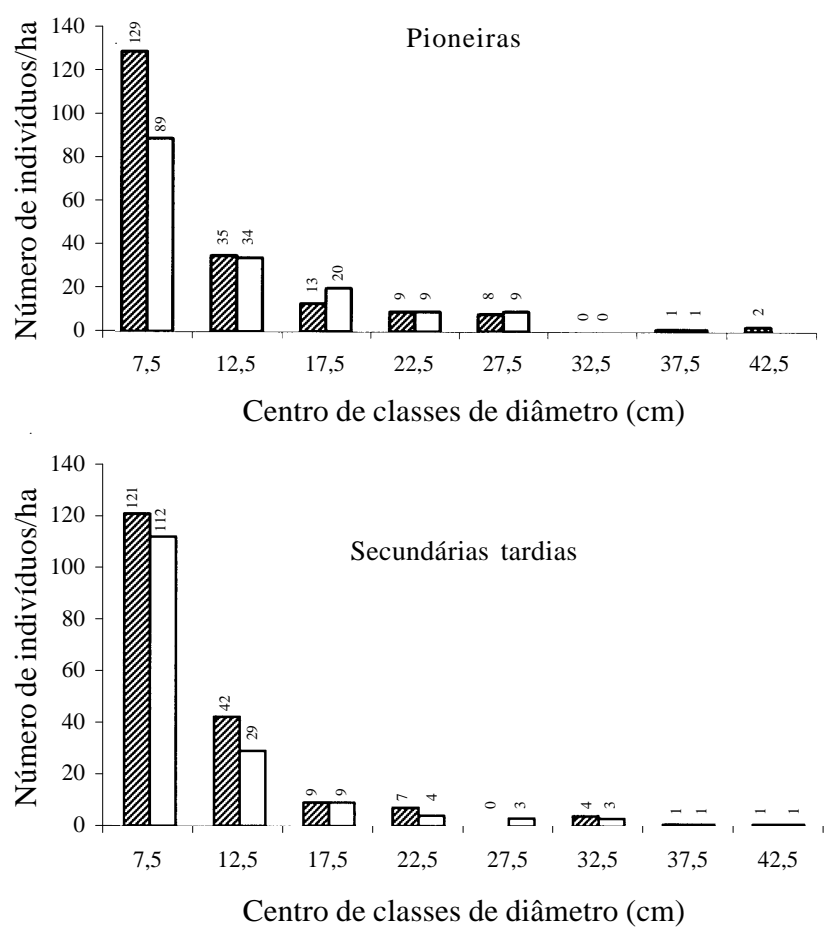

Figura 1. Distribuição do número de indivíduos vivos por hectare nas classes de diâmetro amostrados nos levantamentos realizados em 1984 e 1998 e para os grupos ecológicos das pioneiras, secundárias iniciais e secundárias tardias na Mata da Biologia, situada no câmpus da Universidade Federal de Viçosa,Viçosa, MG. $\square=1984$; $\square=1988$. 

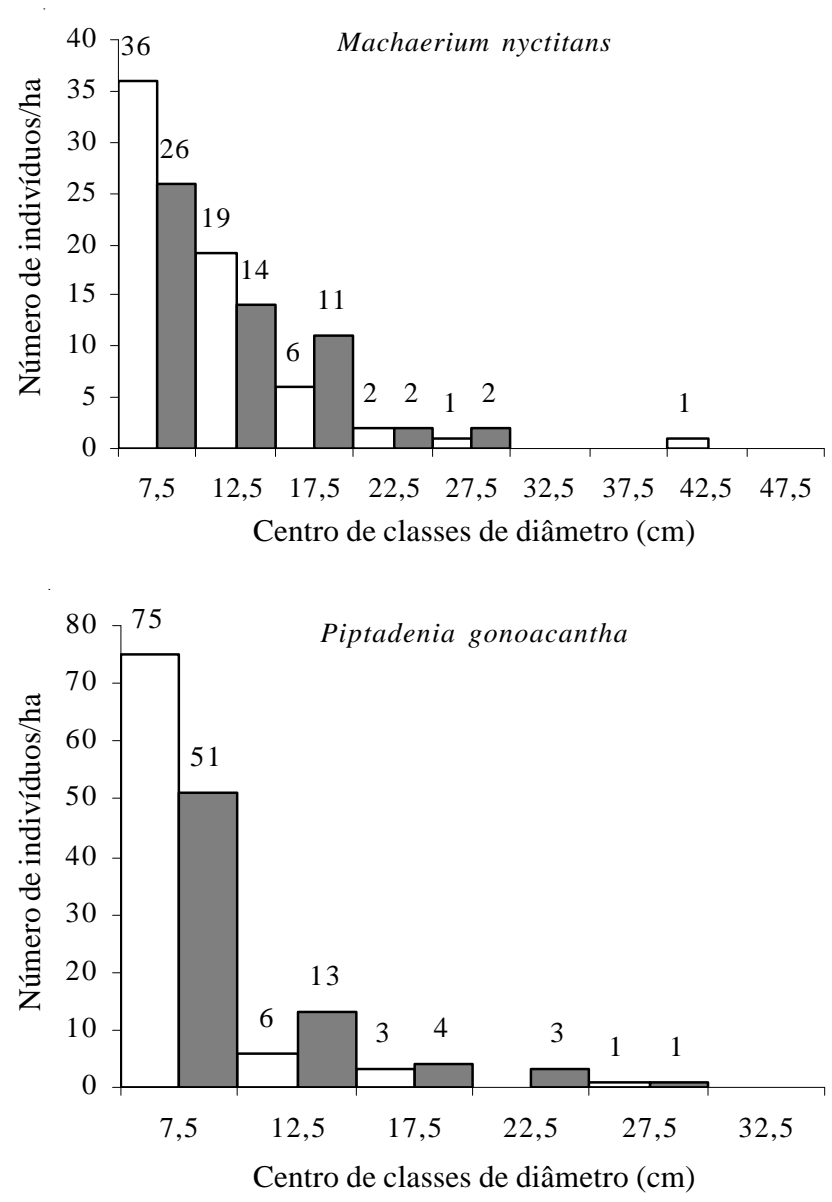

Figura 2. Distribuição do número de indivíduos nas classes de diâmetro das espécies pioneiras Machaerium nictitans e Piptadenia gonoacantha amostradas nos levantamentos realizados em 1984 e 1998 na Mata da Biologia, situada no câmpus da Universidade Federal de Viçosa,Viçosa, MG. $\square=1984 ; \square=1988$.

sucessional, a espécie em questão apresente uma distribuição diamétrica mais ampla.

As espécies Casearia ulmifolia e Rollinia sylvatica (Fig. 5), apresentaram distribuições diamétricas similares, formando um grupo dentro das secundárias iniciais. Todas possuem indivíduos exclusivamente nas menores classes de diâmetro, possivelmente devido a características genéticas (Silva Júnior et al. 1987).

Outro grupo de secundárias iniciais é formado por Sorocea bonplandii, Coutarea hexandra, Siparuna guianense e Trichilia pallida (Fig. 6). Suas distribuições, tanto em 1984 quanto em 1998, incluíram muitos indivíduos na menor classe de diâmetro e queda acentuada nas classes subseqüentes. Já Plinia glomerata pôde ser considerada um caso a parte. Devido às suas características, pequeno porte e perfilhamento, seus indivíduos estão totalmente concentrados na menor classe diamétrica (centro de classe 7,5cm). Em 1984 foram amostrados cinco indivíduos e em 1998, este número subiu para 27.

Como as espécies secundárias tardias entraram no perfil há menos tempo, Protium warmingianum foi a única que pôde ser analisada devido ao reduzido número de indivíduos das demais. Essa espécie possui uma distribuição descontínua e com tendência a "J" reverso (Fig. 7). Vale salientar que a ausência de representante na classe de diâmetro de $27,5 \mathrm{~cm}$ deu-se, provavelmente, em função do método, uma vez que a amplitude de classe foi preestabelecida visando a comunidade, podendo não representar fielmente a distribuição de algumas espécies.

Na Fig. 8 está representada a distribuição diamétrica do grupo das espécies raras contempladas nas amostragens de 1984 e 1998. Nos dois levantamentos, a maior parte das espécies está agrupada na primeira classe diamétrica. Em 1984, cinco espécies foram encontradas em classes diamétricas superiores: duas secundárias iniciais (Ocotea pulchella e Cordia bullata), e duas secundárias

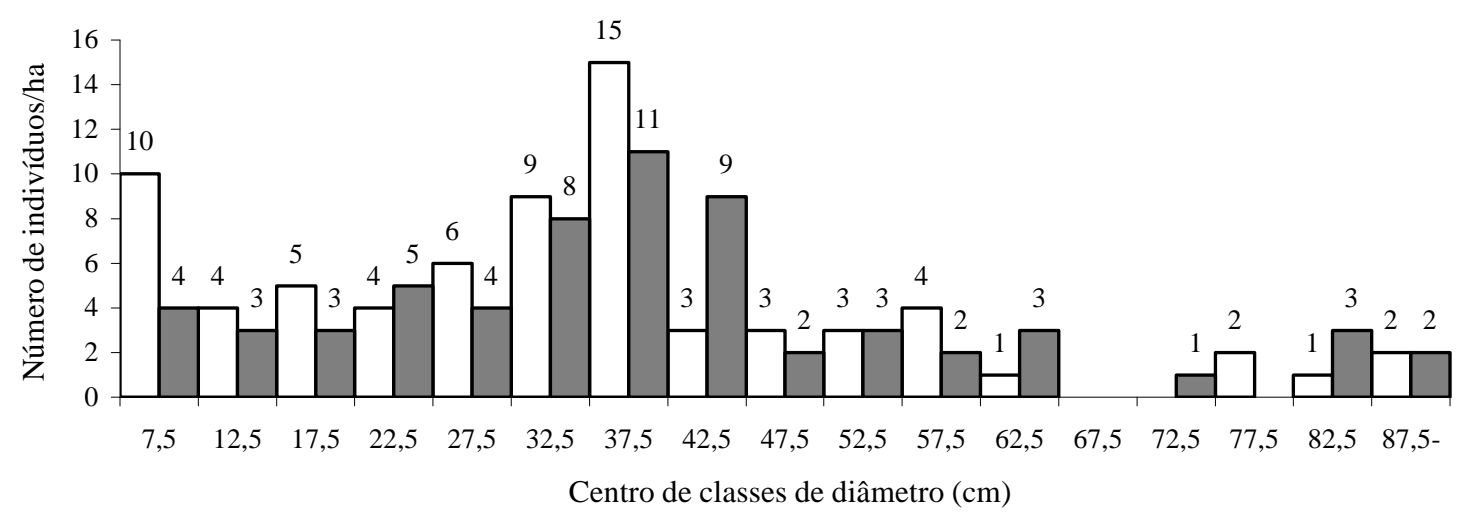

Figura 3. Distribuição do número de indivíduos nas classes de diâmetro da espécie secundária inicial Anadenanthera colubrina amostrada nos levantamentos realizados em 1984 e 1998 na Mata da Biologia, situada no câmpus da Universidade Federal de Viçosa, Viçosa, MG. $\square=1984 ; \square=1988$. 

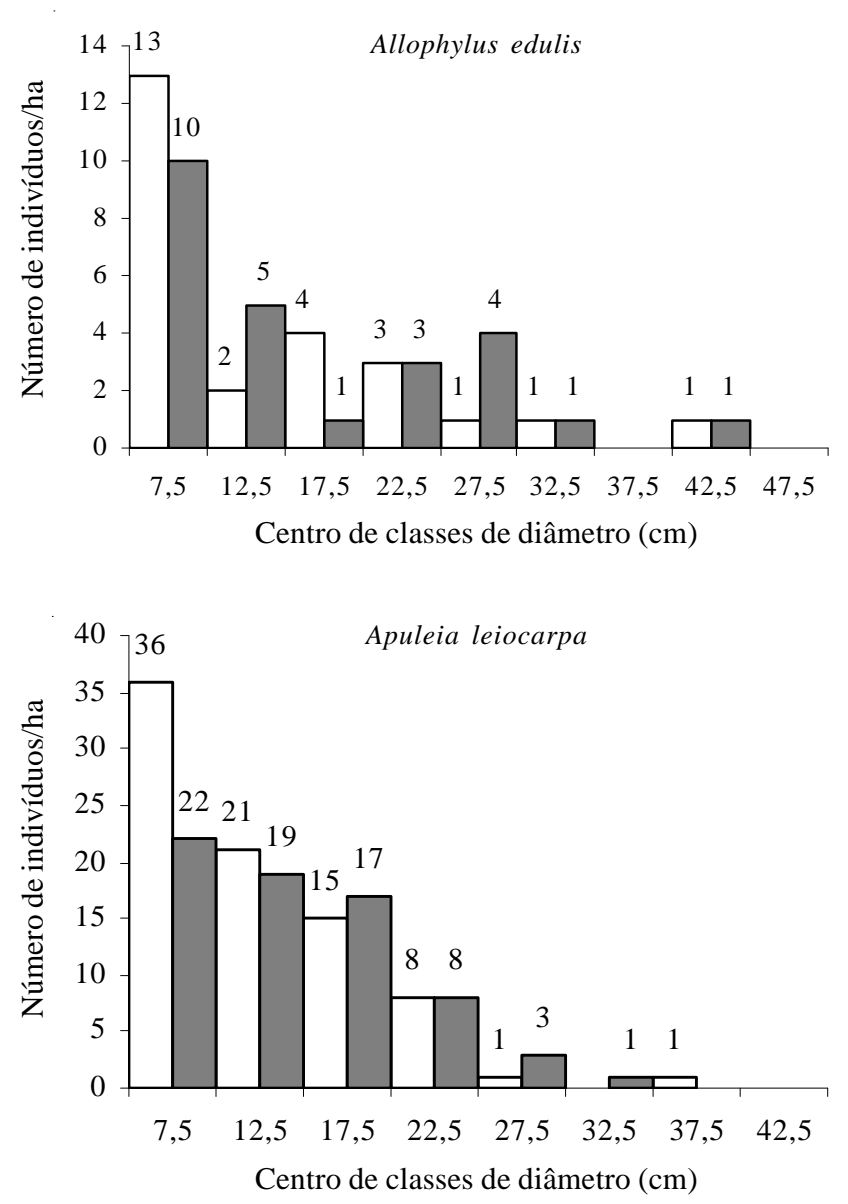

Figura 4. Distribuição do número de indivíduos nas classes de diâmetro das espécies secundárias iniciais Allophylus edulis e Apuleia leiocarpa amostradas nos levantamentos realizados em 1984 e 1998 na Mata da Biologia, situada no câmpus da Universidade Federal de Viçosa, Viçosa, MG. $\square=1984$; $\square=1988$.

tardias (Cariniana legalis e Aniba firmula) na classe de $20 \mathrm{~cm}$, e uma pioneira (Cecropia hololeuca), na classe de 40cm. Em 1998 foram encontradas apenas três espécies nas classes acima de $10 \mathrm{~cm}$ : $O$. pulchella e Trichilia elegans, esta última secundária tardia, na classe de $20 \mathrm{~cm}$, e $C$. hololeuca, na classe de $40 \mathrm{~cm}$.

Distribuição das alturas - A Tab. 4 representa o número de indivíduos por grupos ecológicos em cada estrato da floresta, enquanto na Tab. 2 estão relacionadas as espécies com seus respectivos grupos ecológicos, número de indivíduos encontrados em cada estrato e dispersão de altura. O número de cada espécie corresponde àquele utilizado nos gráficos de altura.

A altura total média das árvores foi igual a $8,7 \mathrm{~m}$ e o desvio-padrão foi de $4,4 \mathrm{~m}$. Dessa forma, o estrato inferior compreendeu todos os indivíduos com altura menor que 4,2m; o estrato médio, os indivíduos com altura igual ou maior a 4,2 e menor que $13,1 \mathrm{~m}$; e o
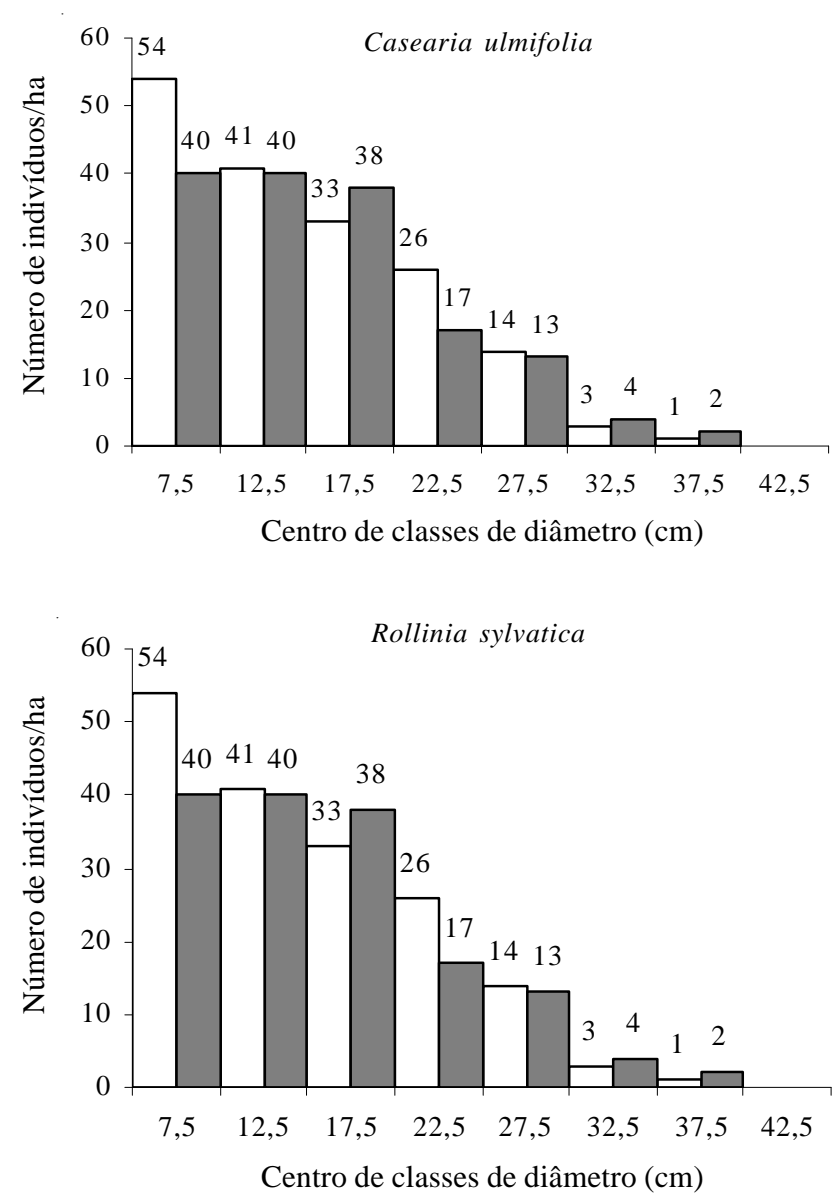

Figura 5. Distribuição do número de indivíduos nas classes de diâmetro das espécies secundárias iniciais Casearia ulmifolia e Rollinia sylvatica amostradas nos levantamentos realizados em 1984 e 1998 na Mata da Biologia, situada no câmpus da Universidade Federal de Viçosa, Viçosa, MG. $\square=1984 ; \square=1988$.

estrato superior, os indivíduos com altura igual ou maior a $13,1 \mathrm{~m}$.

No estrato inferior, o grupo das secundárias iniciais foi o que se apresentou com maior densidade, 75 indivíduos (85,2\%). Desses, 33 indivíduos pertenciam a Siparuna guianense, espécie típica de submata, que se estabelece mesmo em locais onde o dossel não se apresenta fechado (indiferente). Outra espécie de submata bem representada foi Plinia glomerata, com 14 indivíduos. É importante ressaltar a pequena representatividade dos indivíduos do grupo das pioneiras, o que indica que o estádio de sucessão da fitocenose não pode ser considerado inicial, uma vez que está a sugerir baixa regeneração de espécies pioneiras.

O estrato médio também foi dominado pelas secundárias iniciais com 1.199 indivíduos $(80,8 \%)$, com $7,9 \%$ para o grupo das pioneiras e $11,3 \%$ para o grupo das secundárias tardias. Sorocea bonplandii, 


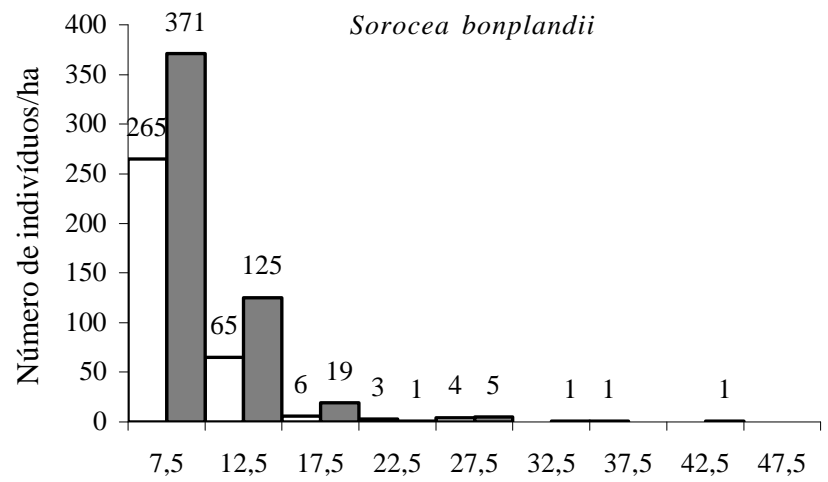

Centro de classes de diâmetro $(\mathrm{cm})$

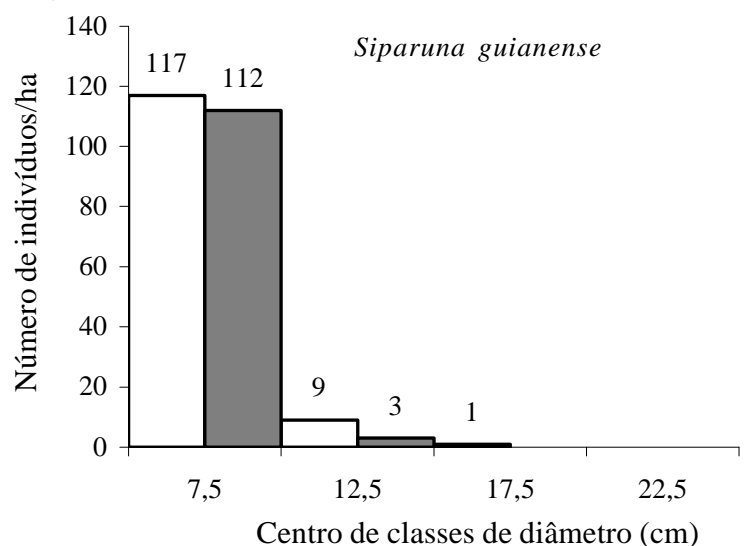

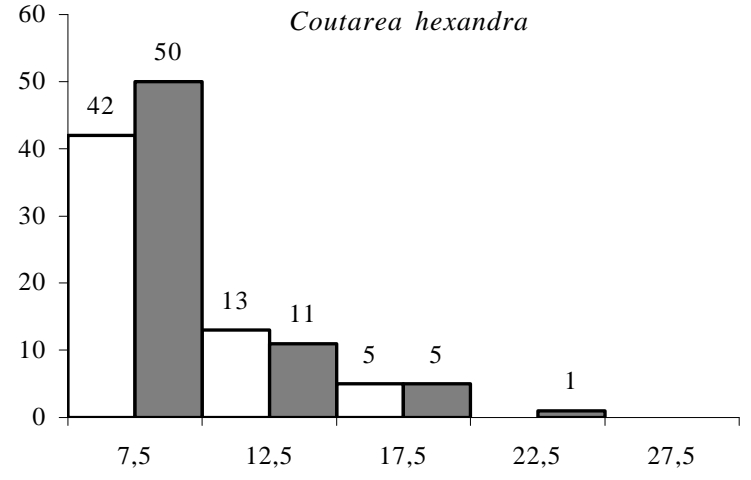

Centro de classes de diâmetro $(\mathrm{cm})$

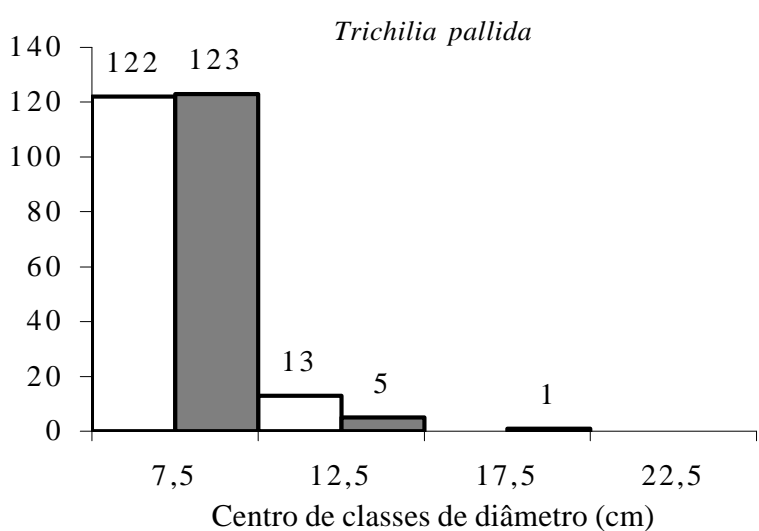

Figura 6. Distribuição do número de indivíduos nas classes de diâmetro das espécies secundárias iniciais Sorocea bonplandii, Coutarea hexandra, Siparuna guianense e Trichilia pallida amostradas nos levantamentos realizados em 1984 e 1998 na Mata da Biologia, situada no câmpus da Universidade Federal de Viçosa, Viçosa, MG. $\square=1984$; $\square=1988$.

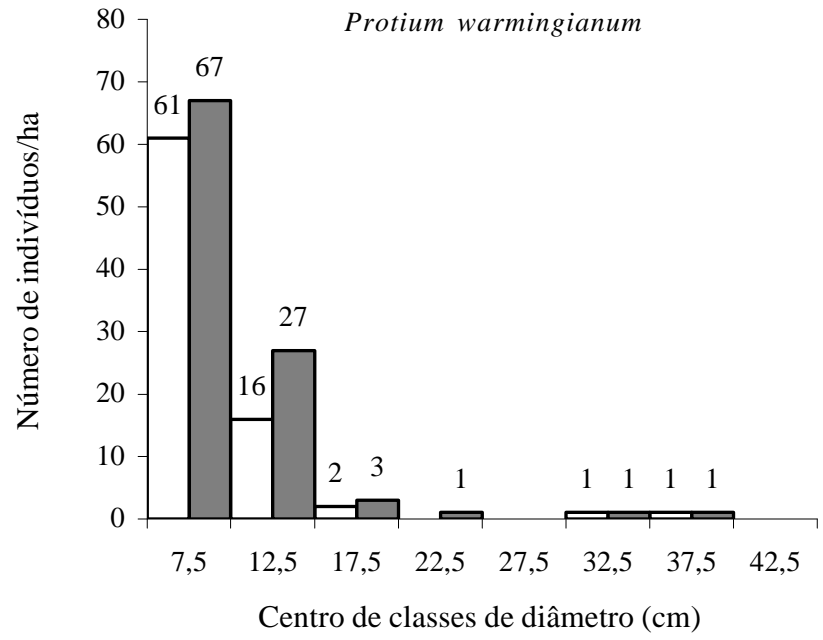

Figura 7. Distribuição do número de indivíduos nas classes de diâmetro da espécie secundária tardia Protium warmingianum amostradas nos levantamentos realizados em 1984 e 1998 na Mata da Biologia, situada no câmpus da Universidade Federal de Viçosa, Viçosa, MG. $\square=1984 ; \square=1988$.

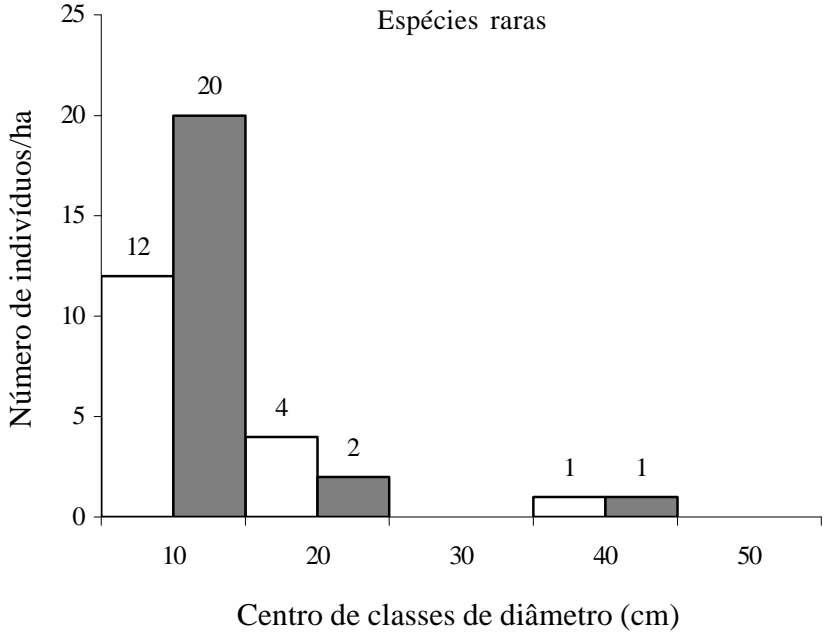

Figura 8. Distribuição do número de indivíduos nas classes de diâmetro das espécies raras amostradas nos levantamentos realizados em 1984 e 1998 na Mata da Biologia, situada no câmpus da Universidade Federal de Viçosa, Viçosa, MG. $\square=1984 ; \square=1988$. 
Tabela 4. Número de indivíduos por grupo ecológico nos estratos inferior, médio e superior das espécies encontradas no levantamento realizado em 1998, na Mata da Biologia, situada no câmpus da Universidade Federal de Viçosa, Viçosa, MG. ht = altura total.

\begin{tabular}{|c|c|c|c|c|c|c|}
\hline \multirow{2}{*}{$\begin{array}{l}\text { Grupos ecológicos } \\
\text { Pioneiras }\end{array}$} & \multicolumn{2}{|c|}{$\begin{array}{l}\text { Estrato inferior } \\
(\mathrm{ht} \geq 4,21 \mathrm{~m})\end{array}$} & \multicolumn{2}{|c|}{$\begin{array}{c}\text { Estrato médio } \\
(4,21 \mathrm{~m}<\mathrm{ht} \geq 13,09 \mathrm{~m})\end{array}$} & \multicolumn{2}{|c|}{$\begin{array}{l}\text { Estrato superior } \\
(\mathrm{ht}>13,09 \mathrm{~m})\end{array}$} \\
\hline & 9 & $10,2 \%$ & 117 & $7,9 \%$ & 36 & $14,2 \%$ \\
\hline Secundárias iniciais & 75 & $85,2 \%$ & 1199 & $80,8 \%$ & 205 & $80,8 \%$ \\
\hline Secundárias tardias & 4 & $4,6 \%$ & 168 & $11,3 \%$ & 13 & $5,1 \%$ \\
\hline Total & 88 & $100 \%$ & 1484 & $100 \%$ & 254 & $100 \%$ \\
\hline
\end{tabular}

secundária inicial, apresentou o maior número de indivíduos (506), perfazendo 34,1\%. Dentre as secundárias tardias, Protium warmingianum representou 57,7\% (97 indivíduos). Já em relação às pioneiras, Piptadenia gonoacantha e Machaerium nictitans somaram $80,3 \%$ dos indivíduos.

No estrato superior, as secundárias iniciais contribuíram com $80,7 \%$ dos indivíduos. Duas espécies foram as mais abundantes nesse estrato, Casearia ulmifolia e Anadenanthera colubrina, com 56 e 55 indivíduos, respectivamente. As duas espécies representaram $54,2 \%$ dos indivíduos do grupo das secundárias iniciais, estando o restante distribuído entre as demais 22 espécies. Como nos outros estratos, no grupo das pioneiras, as espécies Piptadenia gonoacantha e Machaerium nictitans são as mais abundantes, com $66,7 \%$ dos indivíduos. Em relação às secundárias tardias, observou-se equilíbrio entre as espécies, não havendo alguma que tivesse se destacado.

$\mathrm{Na}$ Tab. 5 está representado o número de espécies por grupo ecológico em cada estrato. Entre as espécies pioneiras, três foram observadas exclusivamente no estrato médio (Attalea dubia, Croton floribundus e Mabea fistulifera) e duas exclusivamente no estrato superior (Cecropia hololeuca e Sapium glandulatum).

Tabela 5. Número de espécies por grupo ecológico encontrado nos estratos inferior, médio e superior, encontradas no levantamento realizado em 1998, na Mata da Biologia, situada no câmpus da Universidade Federal de Viçosa, Viçosa, MG.

\begin{tabular}{lccc}
\hline \multirow{2}{*}{ Grupos ecológicos } & \multicolumn{3}{c}{ Número de espécies por estrato } \\
\cline { 2 - 4 } & Inferior & Médio & Superior \\
\hline Pioneiras & 2 & 7 & 6 \\
Secundárias iniciais & 16 & 53 & 24 \\
Secundárias tardias & 3 & 28 & 8 \\
Total & 21 & 88 & 38 \\
\hline
\end{tabular}

Em relação às secundárias iniciais, apenas uma espécie (Psychotria carthagenensis) foi encontrada somente no estrato inferior, 22 foram encontradas no estrato médio e duas no estrato superior (Cordia sylvestris e Ocotea pulchella). Ainda em relação ao grupo das secundárias iniciais, Amaioua guianensis somente foi encontrada no estrato médio com 12 indivíduos e Seguieria americana, também só foi encontrada no mesmo estrato, com seis indivíduos.

Das secundárias tardias, 18 são exclusivas do estrato médio e apenas uma, Endlicheria paniculata, foi encontrada apenas no estrato superior. A espécie Carpotroche brasiliensis apresentou seus oito indivíduos no estrato médio. Outra espécie restrita ao estrato médio foi Eugenia leptoclada, com sete indivíduos.

No estrato inferior, as famílias que obtiveram maior representatividade foram Monimiaceae 37,5\% dos indivíduos (todos da espécie Siparuna guianense), Myrtaceae com 18,2\%, Meliaceae e Moraceae com $9,1 \%$ cada uma, e Mimosaceae com $7,5 \%$. Já no estrato médio, as famílias mais abundantes foram Moraceae com $35,4 \%$, Flacourtiaceae com 8,6\%, Meliaceae com $8,3 \%$, Burseraceae com 6,5\% (representada unicamente por Protium warmingianum), Monimiaceae com 6,5\%, Rubiaceae com 5,6\%, Fabaceae $4,4 \%$, Mimosaceae com 4,2\%. No estrato superior, Mimosaceae contribuiu com 30,3\% dos indivíduos amostrados, Flacourtiaceae 26,8\%, Caesalpiniaceae $12,6 \%$, Fabaceae $7,5 \%$ e Moraceae $5,5 \%$.

Leitão Filho (1982), ao associar a composição florística de família com a estratificação vertical das matas de planalto (Florestas Estacionais Semideciduais do Estado de São Paulo), observou que no primeiro estrato (15 a $20 \mathrm{~m})$ e entre as emergentes (acima de $20 \mathrm{~m}$ ) aparecem basicamente espécies de Leguminosae, Apocynaceae e Anacardiaceae. Outras famílias como Rutaceae, Lauraceae e Euphorbiaceae são bem representadas. O estrato médio (4 a $12 \mathrm{~m}$ ) é caracteristicamente rico em Meliaceae, Myrtaceae, 
Rutaceae, Euphorbiaceae e Lauraceae. Esse autor notou que a diversidade é maior nos primeiros estratos em relação aos menores (abaixo de $15 \mathrm{~m}$ ), excetuando-se o estrato herbáceo, por não ter sido contemplado no trabalho em questão.

No fragmento ora estudado, apenas no estrato superior as observações corresponderam àquelas referidas por Leitão Filho (1982) para as matas de planalto do Estado de São Paulo.

Nas Fig. 10, 11 e 12, são apresentadas as distribuições das alturas para as espécies amostradas no levantamento fitossociológico realizado em 1998. Como pode ser observado na Fig. 9, as espécies pioneiras ficaram distribuídas, em sua maioria, pelos estratos médio e superior, sendo que seis espécies apresentaram-se com indivíduos acima de $15 \mathrm{~m}$. Apenas Machaerium nictitans e Piptadenia gonoacantha foram encontradas no estrato inferior, entretanto com poucos indivíduos. Analisando a Fig. 10, constatou-se que a maioria dos indivíduos das espécies do grupo das secundárias iniciais foi encontrada em torno de $10 \mathrm{~m}$. Grande parte dessas espécies possui distribuição ampla de indivíduos, abrangendo dois ou três estratos. Outro fato relevante é a presença das secundárias iniciais com indivíduos acima de $15 \mathrm{~m}$, dominando o dossel superior. Pela Fig. 11, não foi possível identificar no grupo das secundárias tardias predomínio de

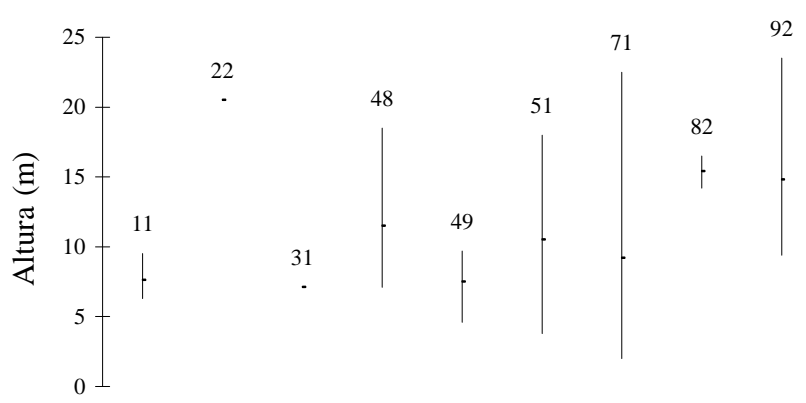

Figura 9. Distribuição das alturas das espécies pioneiras amostradas no levantamento realizado em 1998 na Mata da Biologia, situada no câmpus da Universidade Federal de Viçosa, Viçosa, MG. Cada traço vertical corresponde à diferença entre a altura total do indivíduo mais alto e a altura total do indivíduo mais baixo, sendo o ponto a altura média calculada para a espécie. Os números dos traços são os mesmos que ordenam as espécies na Tab. 4.

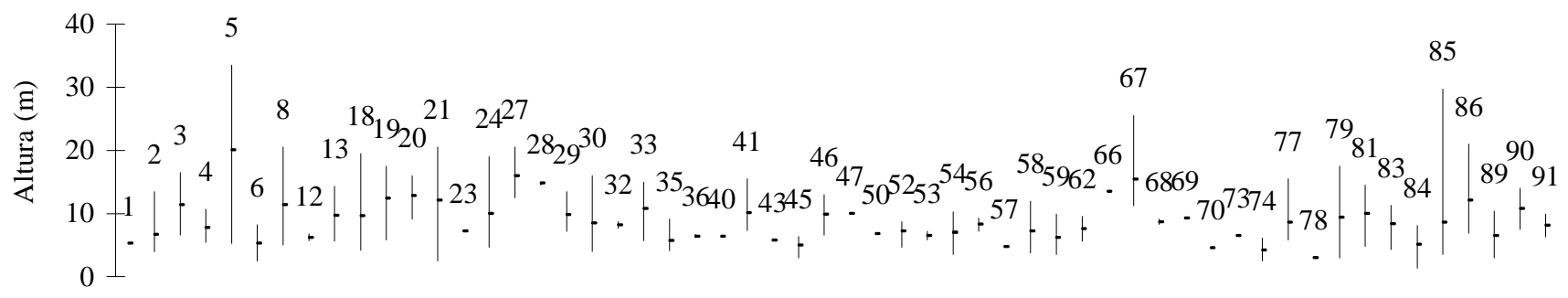

Figura 10. Distribuição das alturas das espécies pertencentes ao grupo das secundárias iniciais amostradas no levantamento realizado em 1998 na Mata da Biologia, situada no câmpus da Universidade Federal de Viçosa, Viçosa, MG. Cada traço vertical corresponde à diferença entre a altura total do indivíduo mais alto e a altura total do indivíduo mais baixo, sendo o ponto a altura média calculada para a espécie. Os números dos traços são os mesmos que ordenam as espécies na Tab. 4.

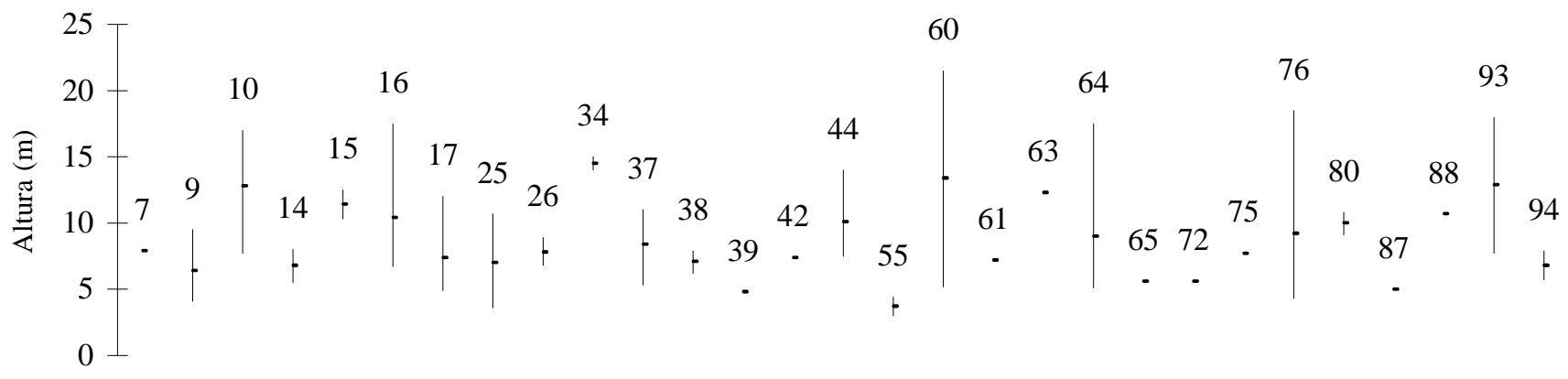

Figura 11. Distribuição das alturas das espécies pertencentes ao grupo das secundárias tardias amostradas no levantamento realizado em 1998 na Mata da Biologia, situada no câmpus da Universidade Federal de Viçosa, Viçosa, MG. Cada traço vertical corresponde à diferença entre a altura total do indivíduo mais alto e a altura total do indivíduo mais baixo, sendo o ponto a altura média calculada para a espécie. Os números dos traços são os mesmos que ordenam as espécies na Tab. 4. 


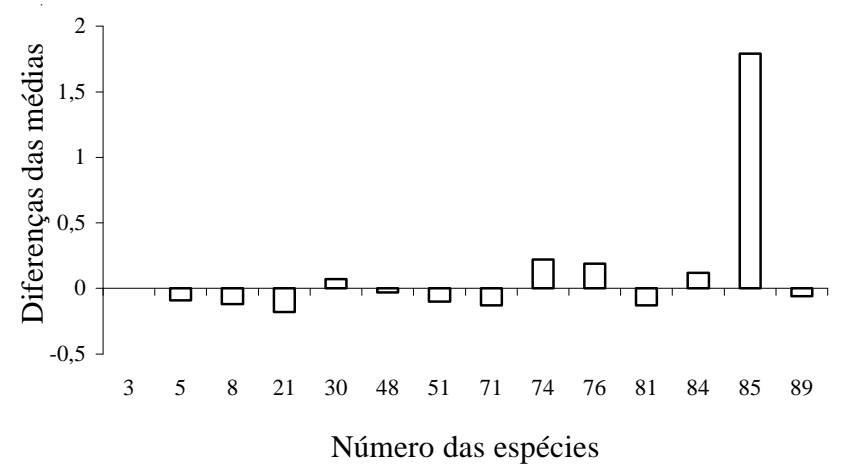

Figura 12. Diferenças das médias do número de indivíduos calculadas pelo teste "t" de Student, para as espécies de maior densidade absoluta (DA) amostradas nos levantamentos de 1984 e 1998, realizados na Mata da Biologia, situada no câmpus da Universidade Federal de Viçosa, Viçosa, MG. Os números de identificação correspondem aos que ordenam as espécies na Tab. 2.

indivíduos em qualquer faixa de altura. As espécies se mostraram bem distribuídas nos três estratos. A maioria delas apresentou grande amplitude na distribuição de altura.

Mortalidade - A estrutura das populações vegetais se caracteriza pela dinâmica, ou seja, novos indivíduos se estabelecem com o passar do tempo, ocupando as posições deixadas pela morte de indivíduos maduros. Se em uma população o recrutamento exceder a mortalidade, a densidade da população aumenta, e vice-versa. Muitas variáveis interferem nesse balanço, algumas são intrínsecas (produção de sementes, ciclo de vida) e outras extrínsecas (flutuação da população de animais predadores de sementes, aumento da precipitação média), o que demonstra a complexidade da dinâmica de populações (Daubenmire 1968).

Em 1998 foram encontrados 151 indivíduos mortos em pé. Os indivíduos que não haviam sido etiquetados na primeira amostragem foram devidamente marcados, não sendo considerados nos cálculos dos parâmetros fitossociológicos. Dos indivíduos mortos em pé, 124 $(82,2 \%)$ foram plaqueados na primeira amostragem. Essa informação não permite precisar exatamente há quanto tempo esses indivíduos morreram, mas oferecem alguns indícios sobre a dinâmica da mortalidade.

Associando os indivíduos marcados em 1984 que morreram e caíram, com os que morreram e continuam em pé, obtêm-se o total de 214. Desses, 41 são do grupo das pioneiras, 149 são secundárias iniciais, 17 são secundárias tardias e sete foram considerados indeterminados por não terem sido identificados no primeiro levantamento. $\mathrm{O}$ grupo das pioneiras foi o que teve a maior taxa de mortalidade nesse período, com $20,8 \%$, contra $11,2 \%$ e $10,4 \%$, das secundárias iniciais e tardias, respectivamente. A taxa de mortalidade dos indivíduos amostrados em 1984, para o estande como um todo, foi de $12,6 \%$.

Lang \& Knight (1983), trabalhando em floresta tropical localizada no Panamá, observaram que $20 \%$ dos indivíduos amostrados em 1968 morreram durante os 10 anos que precederam o segundo levantamento.

Ferreira et al. (1998) monitoraram por 10 anos quatro áreas com diferentes níveis de intervenção (redução da área basal). No tratamento-testemunho (sem intervenção), a taxa de mortalidade anual foi de 1,4\%. Swaine et al. (1987) encontraram taxas próximas para florestas tropicais (entre 1 e $2 \%$ ), próximo da taxa observada para o presente trabalho $\left(0,9 \%\right.$ ano $\left.^{-1}\right)$.

Trichilia pallida, secundária inicial, foi a espécie que apresentou a maior mortalidade (35,6\%), 48 dos 135 indivíduos amostrados em 1984, morreram durante os 14 anos que antecederam o presente levantamento. Entre as espécies pioneiras, Piptadenia gonoacantha perdeu 29 dos 85 indivíduos encontrados no primeiro levantamento $(34,2 \%)$ e Machaerium nictitans teve $10,8 \%$ de seus indivíduos mortos, ou seja, sete dos 65 amostrados. Apuleia leiocarpa, secundária inicial, perdeu 10 dos 82 indivíduos, com taxa de mortalidade de $12,2 \%$ e, Siparuna guianense, também secundária inicial, teve mortalidade de $21,7 \%$ dos indivíduos amostrados em 1984 (25 dos 115 encontrados anteriormente).

Como pode se depreender, entre as espécies mais abundantes, a mortalidade foi maior entre as pioneiras e secundárias iniciais. Em relação à mortalidade dentro dos grupos ecológicos, o grupo das pioneiras apresentou praticamente o dobro da taxa encontrada nos outros dois. Esses dados, aliados ao recrutamento ocorrido nos grupos das secundárias iniciais e tardias demonstram aumento da representatividade destes grupos dentro do estande, refletindo avanço no desenvolvimento sucessional.

Análise estatística por grupo ecológico - Na Tab. 6 são apresentados os resultados referentes à análise da densidade absoluta (DA) das espécies amostradas com mais de 20 indivíduos, realizada por meio do teste " $\mathrm{t}$ " de Student. Nela, pode-se observar que para as espécies Allophylus edulis, Coutarea hexandra, Siparuna guianense e Trichilia pallida, secundárias iniciais, além das pioneiras Luehea grandiflora e Piptadenia gonoacantha, não foram observadas 
Tabela 6. Lista dos parâmetros estatísticos gerados pelo teste "t" de Student para as espécies de maior densidade absoluta, encontradas na Mata da Biologia, câmpus da UFV. Nsp = número das espécies; Média = número de indivíduos da espécie dividido pelo número total de subparcelas; d.p. = desvio-padrão por espécie por ano de amostragem; $\mathrm{p}=$ valor estatístico por espécie; $\mathrm{s}=$ significativo; $\mathrm{ns}=$ não-significativo.

\begin{tabular}{|c|c|c|c|c|c|c|c|}
\hline \multirow[t]{2}{*}{ Nsp/Nome } & \multicolumn{2}{|c|}{ Média } & \multicolumn{2}{|c|}{ d.p. } & \multirow[t]{2}{*}{$\mathrm{t}$} & \multicolumn{2}{|c|}{$\mathrm{p}$} \\
\hline & 1984 & 1998 & 1984 & 1998 & & & \\
\hline 3. Allophylus edulis & 0,25 & 0,25 & 0,796 & 0,796 & 0,000 & 1,000 & $\mathrm{~ns}$ \\
\hline 5. Anadenanthera colubrina & 0,72 & 0,63 & 0,986 & 0,895 & 2,377 & 0,019 & $\mathrm{~s}$ \\
\hline 8. Apuleia leiocarpa & 0,82 & 0,70 & 1,114 & 1,096 & 2,771 & 0,007 & $\mathrm{~s}$ \\
\hline 21. Casearia ulmifolia & 1,72 & 1,54 & 2,045 & 1,987 & 3,462 & $<0,001$ & $\mathrm{~s}$ \\
\hline 30. Coutarea hexandra & 0,60 & 0,67 & 1,443 & 1,688 & $-1,468$ & 0,145 & $\mathrm{~ns}$ \\
\hline 48. Luehea grandiflora & 0,21 & 0,18 & 0,518 & 0,458 & 1,750 & 0,083 & $\mathrm{~ns}$ \\
\hline 51. Machaerium nictitans & 0,65 & 0,55 & 1,067 & 0,999 & 3,000 & 0,003 & $\mathrm{~s}$ \\
\hline 71. Piptadenia gonoacantha & 0,85 & 0,72 & 1,424 & 1,371 & 1,052 & 0,296 & $\mathrm{~ns}$ \\
\hline 74. Plinia glomerata & 0,05 & 0,27 & 0,219 & 0,617 & $-4,200$ & $<0,001$ & $\mathrm{~s}$ \\
\hline 76. Protium warmingianum & 0,81 & 1,00 & 2,126 & 2,225 & $-2,938$ & 0,004 & $\mathrm{~s}$ \\
\hline 81. Rollinia sylvatica & 0,75 & 0,62 & 1,158 & 0,951 & 2,475 & 0,015 & s \\
\hline 84. Siparuna guianense & 1,15 & 1,27 & 1,789 & 2,197 & $-1,241$ & 0,218 & $\mathrm{~ns}$ \\
\hline 85. Sorocea bonplandii & 3,44 & 5,23 & 3,761 & 4,544 & $-10,172$ & $<0,001$ & $\mathrm{~s}$ \\
\hline 89. Trichilia pallida & 1,35 & 1,29 & 2,051 & 1,783 & 0,502 & 0,617 & $\mathrm{~ns}$ \\
\hline
\end{tabular}

ns se $\mathrm{p}>0,05$

alterações em suas densidades. Já as espécies Anadenanthera colubrina, Apuleia leiocarpa, Casearia ulmifolia, Rollinia sylvatica, do grupo das secundárias iniciais, e Machaerium nictitans, pioneira, tiveram redução em suas densidades absolutas. No entanto, Plinia glomerata e Sorocea bonplandii, ambas pertencentes ao grupo das secundárias iniciais, e Protium warmingianum, secundária tardia, apresentaram aumento de suas densidades.

Na Fig. 12 estão representadas as diferenças das médias do número de indivíduos $\left(\left(\overline{\mathrm{DA}}_{2}-\left(\overline{\mathrm{DA}}_{1}\right)\right.\right.$, para as espécies de maior densidade absoluta nos levantamentos de $1984\left(\overline{\mathrm{DA}}_{1}\right)$ e $1998\left(\overline{\mathrm{DA}}_{2}\right)$, calculadas pelo teste "t" de Student.

Assim sendo, as secundárias iniciais, exceto Plinia glomerata e Sorocea bonplandii, não demonstraram estatisticamente acréscimo na densidade absoluta, reduzindo seu valor ou permanecendo estabilizadas. A mesma situação pôde ser observada para as espécies pioneiras, não havendo exceção nesse caso. Essas constatações revelam tendência de redução da importância desses grupos, ao passo que a única secundária tardia (P. warmingianum), que pôde ser analisada, obteve, estatisticamente, aumento de sua densidade absoluta (DA). Esses fatos demonstram melhoria nas condições de suporte da área, quando se considera os grupos ecológicos mais avançados na escala sucessional.

Na Tab. 7 são apresentados os resultados da análise do teste de qui-quadrado $\left(\chi^{2}\right)$, realizado para comparar a freqüência das espécies nos dois levantamentos. Pode-se observar que somente as espécies Plinia glomerata e Sorocea bonplandii demonstraram variação da frequiência absoluta (FA), sendo a mesma positiva, durante o período de amostragem. As duas espécies são do grupo das secundárias iniciais, tendo $S$. bonplandii distribuição agregada, algumas vezes dominando quase que completamente a parcela onde foi amostrada.

Confrontando a análise estatística de DA e FA, observa-se que Protium warmingianum teve o número de indivíduos aumentado, mas não afetando significativamente sua frequiência. Por ser uma espécie do estádio sucessional mais avançado, a melhoria das condições para o seu estabelecimento e desenvolvimento permitiu o aumento da sua abundância, principalmente em unidades amostrais onde a espécie já ocorria. Apesar da evolução sucessional, tal espécie não apresentou distribuição uniforme, o que explica o fato da freqüência ter se mantido no mesmo nível.

Já Anadenanthera colubrina, Apuleia leiocarpa, Casearia ulmifolia, Machaerium nictitans e Rollinia sylvatica tiveram seus valores de abundância reduzidos, também não refletindo significativamente sobre a frequiência. Essas espécies, por serem de estádios iniciais de sucessão, passam por redução do número de indivíduos, uma vez que ao que tudo indica, as condições ambientais estão ficando 
Tabela 7. Lista dos parâmetros estatísticos gerados pelo teste de qui-quadrado $\left(\chi^{2}\right)$ para as espécies de maior frequiência absoluta, encontradas na Mata da Biologia, câmpus da UFV. Nsp = número da espécie; FA = freqüência absoluta; $\mathrm{p}=$ valor estatístico por espécie; $\mathrm{s}=$ significativo; $\mathrm{ns}=$ não-significativo.

\begin{tabular}{|c|c|c|c|c|c|}
\hline \multirow[t]{2}{*}{ Nsp/Nome } & \multicolumn{2}{|c|}{ FA } & \multirow[t]{2}{*}{$\chi^{2}$} & \multicolumn{2}{|c|}{$\mathrm{p}$} \\
\hline & 1984 & 1998 & & & \\
\hline 3. Allophylus edulis & 16 & 16 & 0,000 & 1,000 & $\mathrm{~ns}$ \\
\hline 4. Amaioua guianensis & 10 & 12 & 0,196 & 0,658 & ns \\
\hline 5. Anadenanthera colubrina & 44 & 40 & 0,325 & 0,569 & ns \\
\hline 8. Apuleia leiocarpa & 46 & 39 & 0,992 & 0,319 & ns \\
\hline 13. Brosimum glaziovii & 7 & 13 & 1,913 & 0,167 & ns \\
\hline 18. Casearia arborea & 12 & 14 & 0,171 & 0,679 & ns \\
\hline 19. Casearia decandra & 15 & 13 & 0,161 & 0,688 & ns \\
\hline 21. Casearia ulmifolia & 64 & 59 & 0,522 & 0,470 & ns \\
\hline 25. Chrysophylum gonocarpum & 13 & 14 & 0,041 & 0,839 & ns \\
\hline 30. Coutarea hexandra & 23 & 24 & 0,027 & 0,869 & $\mathrm{~ns}$ \\
\hline 33. Dalbergia nigra & 13 & 11 & 0,183 & 0,669 & ns \\
\hline 45. Jacaranda macrantha & 10 & 10 & 0,000 & 1,000 & ns \\
\hline 48. Luehea grandiflora & 17 & 15 & 0,145 & 0,703 & ns \\
\hline 51. Machaerium nictitans & 36 & 32 & 0,352 & 0,553 & ns \\
\hline 59. Myrciaria axillaris & 11 & 13 & 0,183 & 0,669 & $\mathrm{~ns}$ \\
\hline 64. Ocotea odorifera & 10 & 10 & 0,000 & 1,000 & $\mathrm{~ns}$ \\
\hline 67. Peltophorum dubium & 10 & 7 & 0,549 & 0,459 & $\mathrm{~ns}$ \\
\hline 71. Piptadenia gonoacantha & 39 & 33 & 0,772 & 0,380 & ns \\
\hline 74. Plinia glomerata & 5 & 21 & 10,944 & $<0,001$ & $\mathrm{~s}$ \\
\hline 76. Protium warmingianum & 28 & 33 & 0,582 & 0,446 & $\mathrm{~ns}$ \\
\hline 81. Rollinia sylvatica & 45 & 42 & 0,181 & 0,670 & $\mathrm{~ns}$ \\
\hline 84. Siparuna guianense & 43 & 41 & 0,081 & 0,776 & $\mathrm{~ns}$ \\
\hline 85. Sorocea bonplandii & 82 & 93 & 5,341 & 0,021 & $\mathrm{~s}$ \\
\hline 86. Sparattosperma leucanthum & 12 & 9 & 0,459 & 0,498 & $\mathrm{~ns}$ \\
\hline 89. Trichilia pallida & 51 & 50 & 0,020 & 0,888 & $\mathrm{~ns}$ \\
\hline
\end{tabular}

ns se $p>0,05$

mais restritivas para esses grupos. Suas freqüências ainda não se reduziram, provavelmente devido à renovação imposta pela abertura de novas clareiras, que agora parecem ser mais dispersas e de menores dimensões.

Analisando o número de espécies por grupos ecológicos encontrados em 1998, pode-se observar que o grupo das pioneiras diminuiu em $66,7 \% \mathrm{em}$ relação ao levantamento de 1984. Processo semelhante ocorreu com as secundárias iniciais, que também reduziram substancialmente $(45 \%)$. Em contrapartida, o grupos das secundárias tardias aumentou $43 \%$ no período.

Foram aplicados três testes de qui-quadrado $\left(\mathrm{c}^{2}\right)$ para analisar se existiam correlações significativas (valor estatístico $\mathrm{p}=0,05$ ) para as alterações no número de indivíduos entre:

- os grupos das pioneiras $x$ secundárias iniciais $x$ secundárias tardias;

- grupo das iniciais (pioneiras + secundárias iniciais) $\times$ o grupo das secundárias tardias; $\mathrm{e}$
- grupo das pioneiras $\times$ secundárias iniciais.

O primeiro teste detectou que as alterações ocorridas nos grupos, redução ou aumento no número de indivíduos, não foram significativas $\left(\chi^{2}=9,09\right.$, grau de liberdade $=4$ e $\mathrm{p}=0,058$ ).

O segundo teste apresentou diferenças significativas $\left(\chi^{2}=7,233\right.$, grau de liberdade $=2 \mathrm{e}$ $\mathrm{p}=0,027)$. O grupo das iniciais perdeu $47,8 \%$ dos indivíduos, enquanto o grupo das secundárias tardias perdeu apenas $20 \%$. Esse padrão se inverte em relação ao crescimento do número de indivíduos. Isso demonstra evolução no desenvolvimento sucessional do estande.

Cerca de um terço das secundárias tardias permaneceram no mesmo nível, sendo este valor o dobro do encontrado para o grupo das iniciais. Pode-se considerar que, apesar da evolução sucessional pela qual passou o estande, o mesmo ainda não alcançou nível de maturidade capaz de dar suporte pleno às espécies tardias.

O terceiro teste constatou que as diferenças não foram significativas, ou seja, o comportamento das 
pioneiras e secundárias iniciais não difere $\left(\chi^{2}=2,02\right.$, grau de liberdade $=2$ e valor estatístico $=0,364)$. O resultado obtido no teste anterior não foi influenciado apenas por um grupo de espécies (pioneiras ou secundárias iniciais), o que reforça a idéia de evolução sucessional para o estande.

Ao se observar a baixa representatividade florística das espécies pioneiras em relação às secudárias tardias; a maior densidade apresentada pelo grupo das secundárias iniciais no estrato inferior em vista do pequeno número de indivíduos das pioneiras; a taxa de mortalidade das pioneiras que apresentou praticamente o dobro da encontrada tanto nas secundárias iniciais quanto nas tardias; o elevado recrutamento das secundárias iniciais e tardias; pode-se concluir que o estande se encontra em estádio intermediário de sucessão.

\section{Referências bibliográficas}

Almeida, D.S. \& Souza, A.L. 1997. Florística e estrutura de um fragmento de Floresta Atlântica, no município de Juiz de Fora, Minas Gerais. Revista Árvore 21(2): 221-230.

Budowski, G. 1965. Distribution of tropical american rain forest species in the light of successional processes. Turrialba 15(1): 40-42.

Crestana, M.S.M.; Toledo Filho, D.V. \& Campos, J.B. 1993. Florestas - sistemas de recuperação com essências nativas. CATI, Campinas, SP.

Daubenmire, R. 1968. Plant communities: a textbook of plant synecology. Harper e Row, New York.

Departamento Nacional de Meteorologia. 1992. Normais climatológicas (1961-1990). SPI, EMBRAPA, Brasília.

Dias, M.C.; Vieira, A.O.S.; Nakajima, J.N.; Pimenta, A.P. \& Lobo, P.C. 1998. Composição florística e fitossociologia do componente arbóreo das florestas ciliares do rio Iapó, na bacia do rio Tibagi, Tibagi, PR. Revista Brasileira de Botânica 21(2): 183-195.

Ferreira, R.L.C.; Souza, A.L. \& Jesus, R.M. 1998. Ingresso e mortalidade em uma floresta secundária de transição. Revista Árvore 22(2): 155-162.

Ferretti, A.R.; Kageyama, P.Y.; Árboez, G.F.; Santos, J.D.; Barros, M.I.A.; Lorza, R.F. \& Oliveira, C. 1995. Classificação das espécies arbóreas em grupos ecológicos para revegetação com nativas no estado de São Paulo. Florestar Estatístico 3(7): 73-77.

Gandolfi, S.; Leitão Filho, H.F. \& Bezerra, C.L.F. 1995. Estudo florístico e caráter sucessional das espécies arbustivoarbóreas de uma floresta mesófila semidecidual no município de Guarulhos, SP. Revista Brasileira de Biologia 55(4): 753-767.

Golfari, L. 1975. Zoneamento ecológico do Estado de Minas Gerais para reflorestamento. Série técnica 3, PRODEPEF/PNUD/FAO/IBDF/Bra-45, Belo Horizonte:

Harper, J.L. 1977. Population biology of plants. Academic, London.
Lang, G.E. \& Knight, D.H. 1983.Tree growth, mortality, recruitment, and canopy gap formation during a 10-year period in a tropical moist forest. Ecology 64(5): 1075-1080.

Leitão Filho, H.F. 1982. Aspectos taxonômicos das florestas do estado de São Paulo. Pp. 197-206. In: Anais do Congresso Nacional Sobre Essências Nativas, Silvicultura em São Paulo. São Paulo 1982. Instituto Florestal, v.16 A, pt.1, São Paulo.

Meyer, H.A. 1952.Structure, growth, and drain in balanced uneven-aged forests. Journal of Forestry 50: 85-92.

Moraes, V.H.F. 1970. Periodicidade de crescimento do tronco em árvores da Floresta Amazônica. Pesquisa Agropecuária Brasileira 5: 315-320.

Mueller-Dombois, D. \& Ellenberg, H. 1974. Aims and methods of vegetation ecology. Willey e Sons, New York.

Pagano, S.N.; Leitão Filho, H.P. \& Cavassan, O. 1995. Variação temporal da composição florística e estrutura fitossociológica de uma floresta mesófila semidecídua - Rio Claro - Estado de São Paulo. Revista Brasileira de Biologia 55(2): 241-258.

Paula, A.; Silva, A.F.; Souza, A.L. \& Santos, F.A.M. 2002. Alterações florísticas e fitossociológicas da vegetação arbórea numa floresta estacional semidecidual em Viçosa - MG. Revista Árvore 26(6): 743-749.

Pielou, E.C. 1975. Ecological diversity. Willey, New York.

Rizzini, C.T. 1963. Nota prévia sobre a divisão fitogeográfica (florístico-sociológica) do Brasil. Revista Brasileira de Geografia 25(1): 3-64.

Rosot, N.C.; Amaral-Machado, S. \& Figueiredo Filho, A. 1982. Análise estrutural de uma floresta tropical como subsídio básico para elaboração de um plano de manejo florestal. Pp. 468-490. In: Anais do Congresso Nacional Sobre Essências Nativas, Silvicultura em São Paulo. São Paulo 1982. Instituto Florestal, v.16 A, pt.1, São Paulo.

Shepherd, G.J. 1996. Fitopac 1, manual do usuário. Universidade Estadual de Campinas, Campinas, SP.

Silva, A.F.; Fontes, N.R.L. \& Leitão Filho, H.F. 2000. Composição florística e estrutura horizontal do estrato arbóreo de um trecho da Mata da Biologia da Universidade Federal de Viçosa - Zona da Mata de Minas Gerais. Revista Árvore 24(4): 397-405.

Silva Filho, S.R. \& Engel, V.L. 1993. Estrutura de um fragmento de mata mesófila semi-decídua secundária tardia e implicações para o manejo. Pp. 343-346. In: Anais do $\mathbf{1}^{\mathbf{0}}$ Congresso Florestal Pan-Americano, $7^{\circ}$ Congresso Florestal Brasileiro. Curitiba 1993. SBS/SBEF, Curitiba, PR.

Silva Júnior, M.C.; Barros, N.F. \& Cândido, J.F. 1987. Relações entre parâmetros do solo e da vegetação de cerrado na Estação Florestal de Experimentação e Paraopeba, MG. Revista Brasileira de Botânica 10: 125-137.

Silva Júnior, M.C. \& Silva, A.F. 1988. Distribuição dos diâmetros dos troncos das espécies mais importantes do cerrado na Estação Florestal Experimental de Paraopeba (EFLEX) - MG. Acta Botanica Brasilica 2(1-2): 107-126.

Sokal, R.R. \& Rohlf, F.J. 1984. Introducción a la bioestatística. (Série de Biología Fundamental, n.5) Espanha, Reverté, Barcelona. 
Swaine, M.D.; Lieberman, D. \& Putz, F.E. 1987. The dynamics of tree populations in tropical forest: a review. Journal Tropical Ecology 3(4): 359-366.

Tabarelli, M; Villani, J.P. \& Mantovani, W. 1993a. Estrutura, composição florística e dinamismo de uma floresta secundária na encosta atlântica - SP. Pp. 340-343. In: Anais do $1^{\circ}$ Congresso Florestal Pan-Americano, $7^{\circ}$ Congresso Florestal Brasileiro. Curitiba 1993. SBS/SBEF, Curitiba, PR.
Tabarelli, M; Villani, J.P. \& Mantovani, W. 1993b. Aspectos da sucessão secundária em trecho da Floresta Atlântica no Parque Estadual da Serra do Mar, SP. Revista do Instituto Florestal 5(1): 99-112.

Veloso, H.P.; Rangel Filho, A.L.R. \& Lima, J.C.A. 1991. Classificação da vegetação brasileira, adaptada a um sistema universal. IBGE, Rio de Janeiro .

Zar, J.H. 1984. Biostatistical analysis. $2^{\text {nd }}$ ed. Prentice-Hall: Englewood Cliffs. 